\title{
Segundo puesto \\ EXPORTACIONES DEL PERÚ Y EL APEC DESDE UNA PERSPECTIVA DE LA DOTACIÓN DE FACTORES (1980-1999)
}

\author{
Arturo Ormeño Sánchez \\ UNIVERSIDAD DEL PACÍFICO
}

\begin{abstract}
Resumen
Como consecuencia de las reformas estructurales de los primeros años de la década de los noventa, el Perú ha logrado revertir la tendencia decreciente de las exportaciones observada durante la segunda mitad de los ochenta. Además, en 1998 se ha incorporado al APEC, hecho que representa un conjunto de posibilidades para el desarrollo del intercambio comercial. En este artículo se busca identificar qué tipo de productos se han beneficiado de este proceso de reformas y cuáles dependerán, con mayor intensidad, del desarrollo de las potencialidades actuales. Asimismo, se trata de establecer qué factores productivos explican estos resultados. Para ello se efectúan estimaciones econométricas, basadas en un modelo del tipo Hecksher-Ohlin ampliado, a una muestra de países del APEC. Los resultados indican que si bien factores como el stock de capital, el área geográfica y la disponibilidad de tierras para el cultivo y la actividad forestal son significativos para explicar la dinámica de las exportaciones, hay otros en los cuales el gobierno puede influir directamente, como el grado de apertura y el nivel educativo de la población.
\end{abstract}

\section{Introducción}

Durante la década de los noventa, se produjeron en el Perú dos hechos importantes que han repercutido en el dinamismo exportador observado en los últimos años y que podrían permitir que éste se mantenga en el futuro. Estos hechos son: la reforma comercial y financiera y el ingreso al Foro de Cooperación Económica Asia-Pacífico (APEC).
El primero de estos eventos se desarrolló a comienzos de la década pasada. Las reformas comerciales que se adoptaron durante esos años apuntaron a reducir el arancel promedio. En sólo tres años (1991-1993) se pasó de una estructura arancelaria compleja (con tasas y sobretasas que determinaban un total de 56 niveles arancelarios) a una estructura arancelaria casi uniforme, donde el $87 \%$ del universo arancelario y el $98 \%$ de las 
importaciones estaban afectos a una tasa de $15 \%$.

De esta manera, en un lapso relativamente corto se eliminó gran parte de las distorsiones a los precios relativos y se colocó al país en una posición expectante a los ojos de los inversionistas extranjeros. La nueva coyuntura impulsó la llegada de capitales del exterior, dirigidos principalmente a aquellos sectores que presentaban mayores oportunidades de crecimiento, las cuales habían sido desaprovechadas previamente. Prueba de ello lo constituye el flujo de inversión extranjera directa, el cual totalizó más de US\$ 9 mil millones durante la última década. Entre los sectores que captaron la mayor cantidad de flujos se encuentran los servicios, el sector energético y el sector financiero y de seguros.

El resultado de esta reforma en el ámbito comercial se tradujo en un mayor grado de apertura comercial y en el incremento sostenido de las exportaciones. En el primer caso, el intercambio comercial como porcentaje del producto bruto interno (PBI) se incrementó de $21,8 \%$ a $34,1 \%$ entre los años 1991 y 2000 . A su vez, du- rante estos años, las exportaciones se incrementaron en US\$ 3622 millones, al pasar de US\$ 3406 millones en 1991 a US\$ 7028 millones en el año 2000.

Por otro lado, durante el año 1998, el Perú fue aceptado como país miembro del APEC. La importancia de pertenecer a este foro radica en la posibilidad de reforzar los lazos de integración y cooperación con un conjunto de países que reúnen más del 50\% del comercio de nuestro país con el mundo. Sin embargo, para impulsar el crecimiento exportador no sólo es necesario mayor integración con mercados tradicionalmente importantes, como Estados Unidos, Japón, Canadá, etc. Adicionalmente se requiere el establecimiento y/o fortalecimiento de lazos comerciales con mercados fundamentales, como China, Hong Kong, Rusia, Australia, Singapur, entre otros.

El objetivo del presente trabajo de investigación es identificar los efectos del proceso de reforma comercial implementado en el Perú a inicios de la década de los noventa sobre la diversificación de las exportaciones. Cabe indicar que éstas se han clasificado de acuerdo con el grado

Saldo de la inversión extranjera en el Perú (mill. US\$)

\begin{tabular}{|lrr|}
\hline Inversiones en: & $\mathbf{1 9 9 1}$ & $\mathbf{2 0 0 1}$ \\
\hline Hidrocarburos $^{1}$ & 59 & 98 \\
Mineras $^{2}$ & 437 & 1689 \\
Financieras y seguros & 106 & 1616 \\
Servicios & 277 & 3851 \\
Industriales & 457 & 1540 \\
Energía & 1 & 1568 \\
Total & 1337 & 10362 \\
\hline
\end{tabular}

1/ Neto de pago de préstamos y depreciación.

2/ Incluye privatización.

Fuente: Conite. 
de participación de los factores productivos empleados en su elaboración. De esta manera, se consideran cuatro tipos de productos de exportación: productos intensivos en recursos naturales, productos intensivos en mano de obra no calificada, productos intensivos en tecnología y productos intensivos en capital humano.

Asimismo, se busca determinar empíricamente si existe relación entre la estructura de las exportaciones de una muestra de países y sus respectivas dotaciones de factores. Para esto se tomará de base analítica la teoría neoclásica del comercio internacional (teorema Hecksher-Ohlin), la cual será probada en una muestra de países miembros del APEC. Esto no sólo permite validar la vigencia de esta teoría para el caso de las exportaciones de este grupo de países, también hace posible conocer las características del comercio y las dotaciones de factores de los países de este bloque, que constituyen mercados potenciales para las exportaciones peruanas.

Los resultados obtenidos señalan que si bien la dotación de los factores tradicionales (tales como capital, trabajo y recursos naturales) mantiene su validez para explicar los movimientos en los flujos de exportaciones de los países de la muestra (miembros del APEC) y en el horizonte de tiempo bajo análisis (19801999), hay otros factores que se deben tomar en cuenta. Estos factores son el grado de apertura comercial, el nivel de educación de la población, el área, la población y la riqueza del país (medida como PBI per cápita).

Precisamente, las políticas gubernamentales pueden enfocarse sobre varios de estos últimos factores (grado de apertura comercial, educación y riqueza per cápi- ta) para mejorar la competitividad del país $\mathrm{y}$, por consiguiente, el bienestar de la población en general.

\section{El Perú y el APEC: análisis estadístico}

\subsection{Perú: comercio internacional y la importancia del APEC}

Los países que integran el APEC representan en conjunto el principal bloque comercial para el Perú. Durante el año 2001, el intercambio comercial con este grupo de países alcanzó el 53,2\% del comercio total, superando de esta manera las participaciones de la Asociación Latinoamericana de Integración (Aladi, 23,7\%) y de la Unión Europea $(23,2 \%)$. En ese mismo año, las exportaciones hacia el APEC ascendieron a US\$ 3664 millones, en tanto que las importaciones llegaron a un total de US\$ 3887 millones. Estas cifras representaron el $52,3 \%$ y $54,2 \%$ de las exportaciones e importaciones totales, respectivamente.

Sin embargo, tanto los niveles de exportaciones e importaciones como el grado de participación del comercio con este bloque económico han variado significativamente a lo largo de la década de los noventa. Esto se explica, en gran medida, por las reformas estructurales aplicadas en el país en los primeros años de esa década. Éstas buscaron hacer eficiente la asignación de recursos y evitar la discriminación entre los diferentes sectores de la economía. En lo que respecta a la reforma comercial, ésta buscó la unificación arancelaria y la eliminación de las restricciones y prohibiciones al comercio exterior introducidas durante la segunda mitad de los ochenta. 
Los resultados de estas reformas se hicieron evidentes a partir de 1992, cuando se revirtió la tendencia decreciente de la participación del comercio internacional en la actividad económica. El índice de apertura comercial, medido como el ratio de la suma de las exportaciones e importaciones sobre el producto bruto interno (X+M/PBI), creció a 23,8\%, luego de haber descendido de $29,8 \%$ en 1988 a $21,8 \%$ en 1991. A partir de este año, el índice registró una notoria recuperación hasta alcanzar $34,1 \%$ en el 2000.

Por otro lado, las exportaciones a dólares constantes de 1990 presentan un notable despegue a partir de 1994. Recién a fines de la década de los noventa se logra igualar los niveles registrados veinte años atrás, tal como se aprecia en el gráfico 1.

En lo que respecta a los efectos de las reformas estructurales en el intercambio comercial del Perú con el APEC, se observa lo siguiente: a) A nivel de bloques económicos, el APEC registró el mayor incremento en la participación del comercio con el Perú durante la década de los noventa.

A lo largo de la última década, se ha observado un significativo incremento de la participación de los países del APEC en el intercambio comercial con el Perú. Mientras que su participación en 1990 fue de 46,9\%, en el año 2001 alcanzó el 53,2\%. Este incremento se obtuvo a costa de la disminución de la participación de los países de la Unión Europea y del Mercado Común del Sur (Mercosur), bloques que registraron caídas de 3,4 y 3,7 puntos porcentuales, respectivamente, en estos dos años.

Sin embargo, es necesario indicar que el dinámico incremento de la participación del APEC en el intercambio comercial del Perú ha respondido prin-

Gráfico 1

Evolución del grado de apertura comercial y las exportaciones durante el periodo 1980-2001

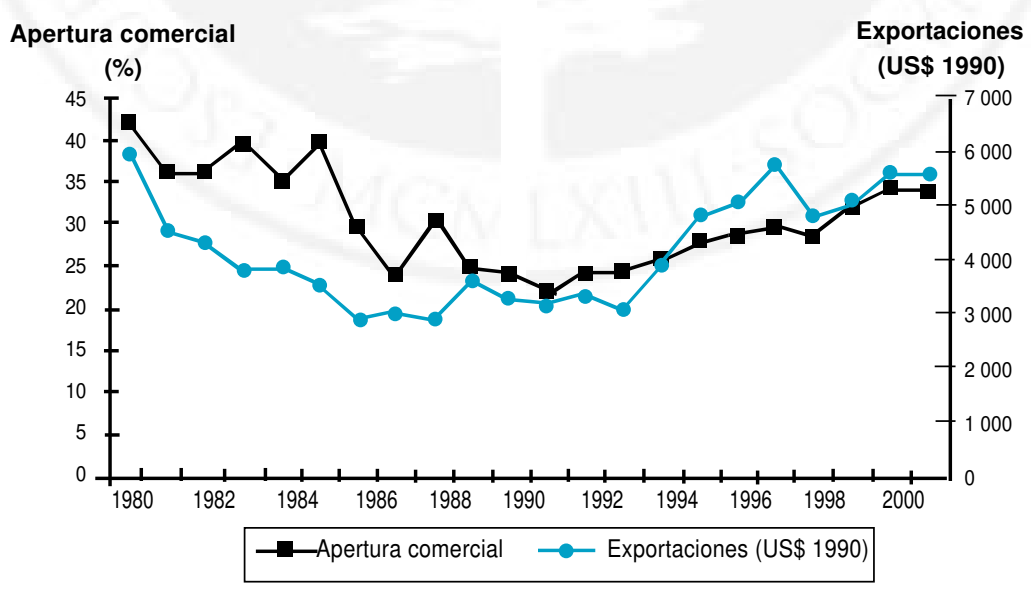

Fuente: BCRP. 
Cuadro 1

Intercambio comercial por principales bloques económicos ${ }^{1}$

(estructura porcentual)

\begin{tabular}{|l|rrr|rrr|rrr|}
\hline & \multicolumn{3}{|c|}{1990} & \multicolumn{3}{|c|}{1998} & \multicolumn{3}{|c|}{2001} \\
\hline & $\mathrm{X}$ & $\mathrm{M}$ & $\mathrm{X}+\mathrm{M}$ & $\mathrm{X}$ & $\mathrm{M}$ & $\mathrm{X}+\mathrm{M}$ & $\mathrm{X}$ & $\mathrm{M}$ & $\mathrm{X}+\mathrm{M}$ \\
APEC $^{2}$ & 48,4 & 45,1 & 46,9 & 53,2 & 55,2 & 54,4 & 52,3 & 54,2 & 53,2 \\
TLC $^{3}$ & 24,7 & 35,6 & 29,6 & 37,5 & 37,8 & 37,7 & 28,8 & 34,2 & 31,5 \\
UE & 31,9 & 19,9 & 26,6 & 22,3 & 21,8 & 22,0 & 26,2 & 20,3 & 23,2 \\
Aladi & 14,0 & 29,9 & 21,0 & 16,8 & 26,0 & 22,2 & 17,2 & 30,3 & 23,8 \\
Grupo Andino & 6,2 & 8,7 & 7,3 & 8,0 & 8,8 & 8,5 & 7,4 & 11,3 & 9,4 \\
Mercosur & 4,6 & 16,1 & 9,7 & 3,7 & 8,7 & 6,7 & 3,6 & 8,4 & 6,0 \\
\hline
\end{tabular}

$\mathrm{X}$ : Exportaciones $\quad \mathrm{M}$ : Importaciones

1/ Los parciales no suman 100 por ciento por la superposición de países entre bloques comerciales.

2/ Foro de Cooperación Económica del Asia Pacífco.

3/ Tratado de Libre Comercio de Norteamérica, firmado en 1993 por los Estados Unidos de América, Canadá y México.

Fuente: Memoria 2001, BCRP.

cipalmente a la evolución del comercio entre nuestro país y Estados Unidos, como se muestra en el cuadro 1. Como puede observarse, el intercambio comercial con el APEC alcanzó su máximo en el año $1998(54,4 \%)$, a pesar de la crisis asiática. Durante ese año se redujo el intercambio comercial con Japón (en 1 punto porcentual), China (2 puntos porcentuales) y el resto de las economías del Asia Pacífico (1 punto). Sin embargo, gracias a la dinámica del comercio con los Estados Unidos, principalmente, y con el resto de las economías americanas, se compensó estos resultados negativos (el comercio con los Estados Unidos se incrementó en 4 puntos porcentuales, y con el resto de países del APEC que pertenecen al continente americano se incrementó en 1 punto porcentual).

b) Las exportaciones dirigidas al APEC son, en su mayoría, de productos pri- marios o tradicionales, aunque en los últimos años se ha incrementado la participación de las exportaciones no tradicionales.

Durante el periodo 1994-2001, la participación de las exportaciones tradicionales sobre el total exportado hacia los países del APEC alcanzó, en promedio, 70,1\%. Si bien esta cifra indica el peso de este tipo de productos, es necesario indicar que esta participación ha ido disminuyendo debido al mayor crecimiento de las exportaciones no tradicionales. Durante este periodo, las exportaciones tradicionales dirigidas a este bloque se incrementaron en $5,8 \%$, frente al incremento de $9,9 \%$ promedio anual de las exportaciones no tradicionales. Esto ha permitido que la participación de las exportaciones de este último tipo de producto se incremente de $27,2 \%$ en 1994 , a $32,8 \%$ en el 2001. 
Cuadro 2

Perú: Exportaciones a los países que conforman el APEC (en US\$ millones)

\begin{tabular}{|c|r|rr|rr|}
\hline \multirow{2}{*}{1} & \multirow{2}{*}{ Total } & \multicolumn{2}{|c|}{ Exportaciones } & \multicolumn{2}{c|}{ Participación (\%) } \\
\cline { 2 - 6 } 1994 & 2207 & 1607 & 600 & 72,8 & 27,2 \\
1995 & 2691 & 2032 & 659 & 75,5 & 24,5 \\
1996 & 2916 & 2175 & 741 & 74,6 & 25,4 \\
1997 & 3480 & 2419 & 1060 & 69,5 & 30,5 \\
1998 & 3019 & 1973 & 1045 & 65,4 & 34,6 \\
1999 & 3083 & 2032 & 1052 & 65,9 & 34,1 \\
2000 & 3697 & 2576 & 1121 & 69,7 & 30,3 \\
2001 & 3546 & 2383 & 1163 & 67,2 & 32,8 \\
\hline
\end{tabular}

Nota: Las exportaciones totales no incluyen el rubro «Otros» ni la reparación de buques o aeronaves extranjeras. Fuente: BCRP.

\section{Gráfico 2}

Grado de concentración en el destino de las exportaciones peruanas en el APEC: 1990 y 2001

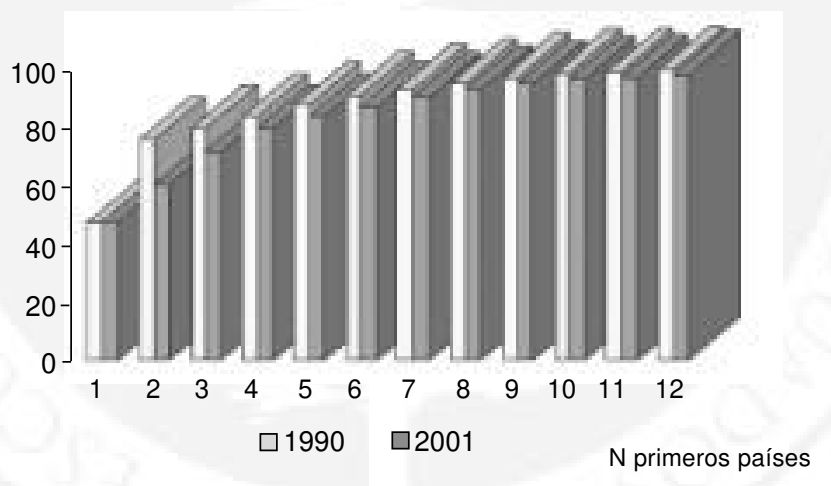

Fuente: Aduanas.

c) Las exportaciones peruanas al APEC se encuentran altamente concentradas en pocos países.

El gráfico 2 muestra la participación acumulada de los primeros países de destino de las exportaciones peruanas que conforman el grupo APEC, durante los años 1990 y 2001. Si bien en estos años se observa una reducción de la concentración, aún dos países, Estados Unidos y Japón, concentran más del $60 \%$ de las exportaciones peruanas a este bloque.

Como se ha señalado anteriormente, Estados Unidos es el principal país de destino y su participación ascendió a 
Cuadro 3

Participación de las exportaciones por tipo de productos (en porcentaje)

\begin{tabular}{|l|c|c|c|c|}
\hline & $\begin{array}{c}\text { Intensivos en } \\
\text { recursos } \\
\text { naturales }\end{array}$ & $\begin{array}{c}\text { Intensivos en } \\
\text { mano de obra } \\
\text { no calificada }\end{array}$ & $\begin{array}{c}\text { Intensivos en } \\
\text { tecnología }\end{array}$ & $\begin{array}{c}\text { Intensivos en } \\
\text { capital } \\
\text { humano }\end{array}$ \\
\hline $1980-1984$ & 87,7 & 5,6 & 3,0 & 2,4 \\
$1985-1989$ & 85,5 & 7,5 & 3,2 & 2,8 \\
$1990-1994$ & 84,5 & 9,0 & 2,7 & 2,8 \\
$1995-1999$ & 83,6 & 8,0 & 3,0 & 2,8 \\
$2000-2001$ & 83,4 & 9,3 & 3,9 & 2,5 \\
\hline
\end{tabular}

Fuente: BCRP.

$47 \%$ en ambos años. En tanto, Japón ha reducido su participación de $28 \%$ a $13 \%$ entre 1990 y el 2001.

A su vez, el resto de países ha mostrado algún patrón oscilante en lo que concierne a sus respectivas participaciones, pero éstas no han afectado de manera muy significativa el índice de concentración presentado en el gráfico 2. En este sentido, otros países importantes como mercados de destino de las exportaciones peruanas son China, Chile, Canadá y México.

d) En lo que respecta a las exportaciones por tipo de productos, a lo largo del periodo 1980-2001 se observa una permanente reducción en la participación de los productos intensivos en recursos naturales, acompañada por el incremento de la participación de los productos intensivos en mano de obra no calificada.

El cuadro 3 muestra la participación promedio de las exportaciones clasificadas según el tipo de producto: intensivos en recursos naturales, intensivos en mano de obra no calificada, intensivos en tecnología, e intensivos en capital humano. Esta clasificación es propuesta por Lawrence Krause (1982) y se elaboró considerando la Clasificación Uniforme del Comercio Internacional (CUCI) ${ }^{1}$.

En este cuadro se observa que la participación de las exportaciones de productos intensivos en recursos naturales cae de $87,7 \%$ en la primera mitad de los ochenta a $83,4 \%$, en promedio, en los años 2000 y 2001. En contraposición, considerando estos mismos periodos, la participación de las exportaciones de productos intensivos en mano de obra no calificada se incrementa de $5,6 \%$ a $9,3 \%$. Este resultado se debe principalmente al significativo incremento de las exportaciones textiles.

\section{2. El APEC y sus miembros}

A continuación se presenta un par de características relativas a los países que conforman el APEC.

El detalle de esta clasificación se presenta en
el apéndice A. 
- Al igual que en el Perú, durante la década de los noventa el grado de apertura comercial de la mayoría de los países que integran el APEC se incrementó.

Entre los países que incrementaron en mayor proporción este índice se encuentran Vietnam, Filipinas, México y Canadá. A excepción de este último, el resto de países mencionados son países denominados en vías de desarrollo. Los países desarrollados, como Estados Unidos, registraron un incremento de $19 \%$, en tanto que Japón retrocedió en $7 \%$ (ver cuadro $1 \mathrm{del}$ apéndice $\mathrm{C}$ ).

- Este proceso de apertura comercial se ha visto reflejado en mayores incrementos de las exportaciones intensivas en tecnología y capital humano, tanto en países en desarrollo como en países desarrollados.

En los países desarrollados, el crecimiento de las exportaciones de los sectores intensivos en trabajo, tecnología y capital humano fue considerable en comparación con el crecimiento del total de las exportaciones. Sin embargo, en todos los casos, excepto uno, el crecimiento de los productos intensivos en recursos naturales fue inferior al total. Este hecho muestra en los sectores transables de estas economías una tendencia cada vez mayor hacia la especialización en productos intensivos en tecnología y en trabajo -especializado o no especializado-, a la vez que una dependencia cada vez menor de productos primarios.

En los países en desarrollo también se observa un gran incremento de los pro- ductos intensivos en tecnología. Este fenómeno estaría explicado, probablemente, por el hecho de que los sectores con alta tecnología podrían estar ligados a capitales muy móviles entre países, de modo que las decisiones de localización de la producción a través de minimización de costos se basarían, principalmente, en la comparación de los sueldos y salarios de las distintas localidades.

Igualmente, en este mismo grupo de países se observa un crecimiento notorio de las exportaciones intensivas en capital humano. Sin embargo, este crecimiento no es tan fuerte como para reducir significativamente la importante dependencia de los productos intensivos en productos primarios.

En cuanto al crecimiento de los productos intensivos en trabajo, éste es mayor al total sólo en 6 de los 19 países presentados. Este hecho permite inferir que la apertura comercial en los países en desarrollo del APEC estaría incidiendo de manera poco significativa en una mayor demanda de trabajo con relación a los demás factores de producción, mientras los recursos primarios continúan siendo el principal factor implícito en las exportaciones totales (ver cuadro 2 del apéndice $\mathrm{C}$ ).

\section{Metodología}

El análisis que se desarrolla en la sección 4 toma como base metodológica el teorema de Hecksher-Ohlin (HOV) ampliado. En su versión simple, este teorema indica que un país con comercio internacional equilibrado exportará el producto que use 
intensivamente aquel factor relativamente abundante en su territorio, e importará aquel producto que incorpore mayoritariamente el factor relativamente más escaso.

Sin embargo, en la vida real, el comercio internacional es influenciado por varios factores que impiden el total cumplimiento de este teorema. Para empezar, hay problemas metodológicos con relación a la movilidad de factores como el capital ${ }^{2}$. Adicionalmente, estudios recientes consideran necesaria la incorporación de variables relativas al nivel de ingreso (teniendo en cuenta que con frecuencia algunos bienes son considerados como superiores o de lujo, o hay sesgos a consumir bienes nacionales o bienes extranjeros -según el caso- a medida que el ingreso se incrementa). Las barreras arancelarias y los costos de transportes también presentan desviaciones relevantes del modelo de HOV.

Todas estas nuevas consideraciones metodológicas motivan la incorporación de variables explicativas adicionales a las variables tradicionales, como el capital, la tierra y el trabajo. El conjunto de variables explicativas que serán incorporadas en las estimaciones se detallan en la siguiente sección. Los interesados en la ex-

2. Existe controversia acerca de cómo debe tratarse el factor capital. Tradicionalmente, éste ha sido considerado como un factor propio de un país. Sin embargo, la literatura más reciente está considerándolo como movible, por lo que no debería afectar la estructura de las exportaciones, ya que ésta última se encuentra afectada por la abundancia doméstica de factores inmóviles y por el precio relativo de estos factores. En este sentido, la nueva propuesta considera la inclusión de la tasa de interés. No obstante, por problemas de homogeneidad en este tipo de data, la inclusión de esta variable ha estado limitada. plicación económica de cómo los factores mencionados anteriormente distorsionan el cumplimiento del teorema HOV normal, pueden consultar el detalle presentado en el apéndice B.

\section{Datos empleados}

\subsection{Variables dependientes}

Las estimaciones econométricas que se realizan en la siguiente sección consideran como variables por explicar las exportaciones de una muestra de 18 países que integran $\mathrm{APEC}^{3}$. Sin embargo, estos datos no son utilizados de manera agregada, sino que previamente han sido clasificados en las siguientes cuatro categorías ${ }^{4}$ :

a) Productos intensivos en recursos naturales.

b) Productos intensivos en mano de obra no calificada.

c) Productos intensivos en tecnología.

d) Productos intensivos en capital humano 5 .

Los datos de las exportaciones totales de los países seleccionados que compren-

3. Estos países son: Australia, Canadá, Chile, China (continental), Hong Kong, Indonesia, Japón, Corea (del Sur), México, Malasia, Nueva Zelanda, Perú, Filipinas, Papua Nueva Guinea, Singapur, Tailandia, Taiwan y Estados Unidos. Por carencia de datos no se incluye a Brunei Darussalam, Rusia y Vietnam.

4. Esta agregación fue propuesta por Lawrence Krause (1982). La descripción de cada uno de los subgrupos en términos de la Clasificación Uniforme del Comercio Internacional (o Standard International Trade Classification) se encuentra detallada en el apéndice A.

5. Como este tipo de clasificación no recoge todos los productos que involucra la Clasificación Uniforme del Comercio Internacional (CUCI), la suma de los diferentes grupos no será igual al total de las exportaciones. 
den el periodo 1980-1995 corresponden a la publicación del APEC: Aspects of Market Integration in APEC: Trade, Foreign Direct Investment and Labor Migration. Adicionalmente, para completar la información correspondiente a la década de los noventa se emplean los datos del PCTAS $^{6}$. Esta base de datos presenta información para el periodo 1995-1999. Debido a que los datos del año en común (1995) de ambas fuentes presentan ligeras discrepancias, se procedió a tomar las tasas de crecimiento anual del PC-TAS para el año 1995, y sobre este total se mantiene la estructura registrada por el PC-TAS.

Debido a que los datos del año en común (1995) de ambas fuentes presentan ligeras discrepancias, se procedió a completar las series de exportaciones totales del «APEC: Aspects...» para el periodo 1995-1999 con la información de las tasas de crecimiento anual presentadas en el PC-TAS. Asimismo, la determinación de la participación de cada tipo de producto de exportación para el periodo 1995-1999 consideró la estructura registrada en el PC-TAS.

En lo que respecta a las exportaciones peruanas, éstas no se encuentran recogidas en el documento «APEC: Aspects...», por lo que se tuvo que efectuar su cálculo para todo el periodo muestral. La fuente de esta información es la Memoria 2000 del Banco Central de Reserva del Perú (BCRP). Se considera como total de exportaciones a la suma de las exportaciones tradicionales y no tradicionales (no se incluye el rubro Otros). Los datos del Perú

6. Trade Analysis System on Personal Computer. Esta base de datos es elaborada por la Oficina de Comercio Internacional de la Unctad. y del resto de países considerados en la estimación se encuentran en el cuadro 3 del apéndice $\mathrm{C}$ ).

Todos los datos relativos a las exportaciones están divididos por la fuerza laboral y en dólares constantes del año 1990, para eliminar los efectos tendenciales asociados al incremento de los precios y de la población.

\subsection{Variables explicativas}

En lo que respecta a las variables explicativas, éstas pueden ser clasificadas en dos tipos: aquellas que hacen referencia a la dotación de factores tradicionales y aquellas que se refieren a las dotaciones de factores alternativos. Se debe destacar que por «dotación» se hace referencia a un conjunto amplio de características de cada país que sean, en cierta medida, inmóviles.

a) Factores tradicionales. En este grupo se encuentran las dotaciones de capital, trabajo y «tierra».

Con relación al primero de estos factores, en la sección metodológica se señaló que debido a que existen algunas opiniones que cuestionan su naturaleza de no movilidad, sería apropiado considerar variables más endógenas, como la tasa de interés doméstica, antes que el stock de capital. Sin embargo, debido a que no se cuenta con estadísticas de tasas de interés lo suficientemente homogéneas que permitan la comparación entre países para un periodo extenso de años, se decidió finalmente considerar el stock de capital. Para esto fue necesario trabajar con las bases de stock de capital disponibles en la página web del Banco Mundial (World Development Indicators Database). Sin embar- 
go, debido a que éstas no se encuentran actualizadas, se procedió a completarlas con información acerca del flujo de inversión, cifras reportadas por el Fondo Monetario Internacional (FMI) en sus Estadísticas financieras.

Los datos de hectáreas dedicadas al cultivo y de área forestal provienen del trabajo de Leamer (1999). De este tipo de datos se cuenta con una observación por década.

Finalmente, la ausencia de alguna variable que mida la existencia de reservas mineras en los países en estudio es una limitación significativa, considerando que hay países mineros como Chile, Perú, México, entre otros. Este hecho podría sesgar los resultados, ocasionar que los factores «tradicionales» se vean reducidos en lo que respecta a sus efectos sobre la estructura de las exportaciones en estos países.

b) Educación. El nivel de educación de la población de un país puede considerarse como un factor no móvil, sobre todo cuando se trata de población adulta (es de esperarse que la población joven puede migrar con mayor facilidad que la adulta). En este sentido, se incorpora como variable aproximada de la dotación educacional al promedio de años de estudios de la población adulta (con 25 o más años de edad). La fuente de estos datos es Barro \& Lee (http://www.cid.harvard.edu/ ciddata/ciddata.html).

c) Apertura comercial. Como se mencionó en la sección anterior, la existencia de barreras al libre comercio de bienes puede afectar la composición y la intensidad del comercio internacional. Nueva- mente, la variable óptima por utilizar debería hacer referencia al grado de trabas para cada tipo de productos. Sin embargo, estos datos no se encuentran disponibles para todos los países considerados en las estimaciones ni para el periodo requerido. En vista de esto, se utiliza la proporción del intercambio comercial $(\mathrm{X}+\mathrm{M})$ como proporción del PBI.

d) PBI per cápita. La introducción de esta variable responde a la necesidad de incorporar al modelo la existencia de algún tipo de sesgo al consumo de bienes nacionales o de preferencias no homotéticas. Estos datos corresponden al Banco Mundial (Heston y Summers, 1991) y fueron obtenidos de la base de datos Penn World Table 5.6 (http://www.nber.org/ pub/pwt56/).

e) Otra variable que también recoge los efectos de la absorción doméstica es el tamaño de la población. Por ello se incorpora esta variable (en logaritmos) en el modelo estimado.

f) Asimismo, se incluye la variable extensión territorial como una variable próxima a las posibilidades que tiene un país por exportar en mayor medida productos intensivos en recursos naturales.

Adicionalmente, se incorporó un índice de sobrevaluación de las monedas de cada uno de los países de la muestra. Como se menciona en la sección metodológica, la variación de los precios relativos no sólo puede generar una situación de desbalance comercial, sino que incluso, teóricamente, invalida la noción de consistencia de Hecksher-Ohlin. Sin embargo, esta variable resultó ser no significativa en las estimaciones efectuadas. 


\section{Resultados}

Las estimaciones efectuadas se realizaron aplicando Mínimos Cuadrados Ordinarios (MCO), técnica que permite determinar la existencia estadística de alguna relación entre dos o más variables. Los datos empleados comprenden observaciones para 18 de los 21 países que integran el APEC 7 . Se considera como variables por ser explicadas las participaciones de cada uno de los cuatro grupos de productos de exportación (intensivos en recursos naturales, intensivos en mano de obra no calificada, intensivos en tecnología, e intensivos en capital humano) en el total de las exportaciones.

Los resultados presentados en el cuadro 4 del apéndice $\mathrm{C}$ se obtienen de tres estimaciones efectuadas. En cada una de ellas, lo que se busca es determinar una relación entre las exportaciones por productos y las variables que indican la dotación de algún tipo de producto. Los datos corresponden a una muestra de 18 países y son reportados con frecuencia anual para el periodo 1980-1999, con frecuencia quinquenal (es decir, como promedio de los subperiodos 1980-1984, 1985$1989,1990-1994$ у 1995-1999) у como promedio por décadas (subperiodos 19801989 y 1990-1999). El empleo de estos datos tiene por objetivo evaluar la consistencia de los resultados obtenidos. En términos econométricos, se busca evaluar la estabilidad de parámetros, así como otorgarle mayor grado de libertad a la primera estimación.

7. Por disponibilidad de datos no se incluyeron en las estimaciones a Brunie Darussalam, Rusia y Vietnam.

\subsection{Dotación de factores tradicionales}

Entre las tres variables «tradicionales» consideradas en las estimaciones, el stock de capital por trabajador (KPW) es la variable más importante para explicar los patrones de las exportaciones. Esta variable es significativa en las ecuaciones que explican la participación de las exportaciones de los productos intensivos en mano de obra no calificada y de los productos intensivos en tecnología. Sin embargo, el efecto de este factor sobre ambos tipos de exportaciones es inverso.

Mientras que los resultados obtenidos indican que el mayor capital invertido favorece la participación de exportaciones del tipo tecnológico, el efecto es contrario en las exportaciones intensivas en mano de obra no calificada.

Dentro del primer tipo de exportaciones se encuentran los productos químicos, los equipos para el procesamiento de data y telecomunicaciones, los aviones, etc. Los países que han registrado mayor participación de este tipo de exportaciones en el periodo bajo análisis son Japón, Estados Unidos y Singapur (con 51,1\%, 49\% y $46,8 \%$, respectivamente). A su vez, éstos son los países del bloque APEC que cuentan con los mayores stocks de capital por trabajador (ver gráfico 3).

Por otro lado, China es uno de los países que registra mayor dependencia de las exportaciones intensivas en mano de obra no calificada $(34,9 \%$ en promedio) y que cuenta, a la vez, con el menor nivel de capital por trabajador (de US\$ 4,2 mil dólares).

El gráfico 3 permite observar las relaciones encontradas. Este gráfico muestra 


\section{Gráfico 3}

Participación de las exportaciones tecnológicas $e$ intensivas en mano de obra no calificada (como \% del total de las exportaciones)

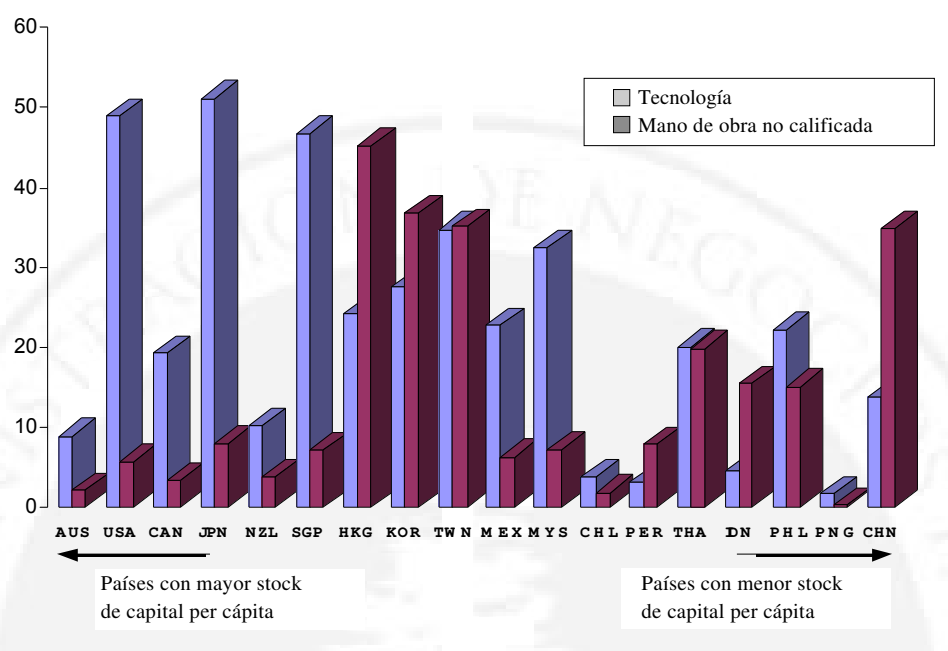

en el eje «X» a los 18 países que conforman el APEC, ordenados de acuerdo con el nivel de stock de capital por trabajador (medido en dólares de 1990). Al inicio de esta formación (más cercano al eje «Y») se encuentra Australia, país que ha registrado un nivel promedio de US\$ 81 mil dólares. En el otro extremo de esta secuencia está China, que, como se indicó previamente, cuenta con un nivel de capital por trabajador de apenas US\$ 4,2 mil dólares.

En lo que respecta a la posición del Perú en el ranking del stock de capital por trabajador a nivel del APEC, nuestro país ocupa el decimotercer lugar, con un nivel de 16,9 mil dólares. En la posición previa se encuentra Chile (23,6 mil dólares), y en la posterior, Tailandia (9,3 mil dólares).

Con relación a las dos variables relativas al factor «tierra» (CROP y FORE), éstas aparecen significativas en las esti- maciones que involucran observaciones referidas al promedio por décadas (estimación $\mathrm{n}^{\circ}{ }^{\mathrm{2}}$ ) y por quinquenios (estimación n. ${ }^{\circ} 3$ ).

En lo referente al número de hectáreas forestales por trabajador (FORE), ésta resulta ser significativa en las ecuaciones que explican la participación de las exportaciones de bienes intensivos en capital humano (con impacto positivo) y de bienes intensivos en recursos naturales (con impacto negativo).

En lo referente a la participación de esta variable en el primer tipo de exportaciones, su presencia indica la disponibilidad de alguna materia prima empleada en este tipo de exportaciones. Entre los países de la muestra que cuentan con elevada participación de este tipo de exportaciones se encuentra Canadá (promedio de $34 \%$ ). A su vez, este país cuenta con elevados niveles de áreas forestales (de 28,8 


\section{Gráfico 4}

Relación entre la participación de las exportaciones intensivas en capital humano y la dotación de hectáreas forestales

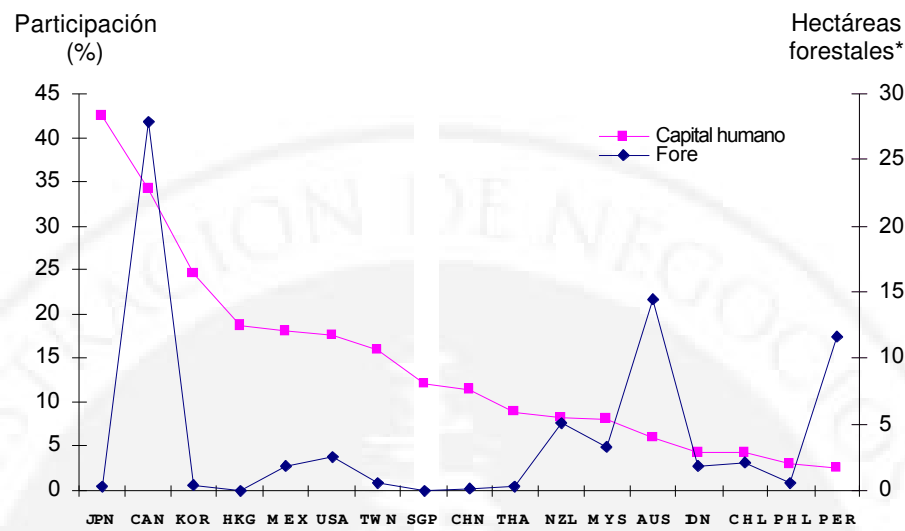

Nota: Entre los países que favorecen una relación positiva entre las exportaciones y la dotación de hectáreas forestales se encuentran Canadá, Nueva Zelanda, Malasia, Indonesia, Chile y Filipinas.

* En miles de hectáreas por trabajador.

Fuente:PC-TAS y APEC: Aspects of Market Integration in APEC: Trade, Foreign Direct Investment and Labor Migration (1999).

mil y 27 mil hectáreas por trabajador como promedio de las décadas de los ochenta y noventa, respectivamente). Aparentemente, esta disponibilidad de recursos sería uno de los factores tras la importancia relativa de este tipo de exportaciones, considerando que en ellas se encuentran las manufacturas que emplean papel.

Por otro lado, la presencia de la variable FORE (con signo negativo) en las exportaciones de productos intensivos en recursos naturales es menos clara. Nuevamente la presencia de Canadá (con elevada disponibilidad de este recurso y con baja participación en el total de sus exportaciones de los bienes intensivos en recursos naturales) podría justificar esta relación. Otro país que respaldaría este resultado sería Chile (elevada participación de este tipo de exportaciones
$(87,5 \%)$, con bajos niveles de este recurso). Sin embargo, países como Japón, Hong Kong y Corea podrían generar la presencia de una relación positiva (baja participación de este tipo de exportaciones y baja disponibilidad de este recurso).

Finalmente, la variable hectáreas de tierras de cultivo por trabajador (CROP) hace su aparición en la ecuación de las exportaciones de productos intensivos en capital humano (estimación n. ${ }^{\circ} 3$ ). Si bien intuitivamente su significancia no es del todo aceptable, su presencia indicaría que la abundancia de tierras de cultivo favorece la producción de otros bienes, exceptuando los intensivos en capital humano.

Antes de proceder con el análisis de los resultados, se debe indicar la omisión (por carencia de información) de variables 
que hagan referencia a la disponibilidad de las reservas mineras de los países de la muestra. Hay que considerar que entre los miembros del APEC se encuentran países mineros, como Chile, Perú y México, por lo que la omisión de esta variable ha afectado los resultados de los modelos estimados (principalmente el relacionado con las exportaciones de productos intensivos en recursos naturales). Sin embargo, dentro de las variables que hacen referencia a los factores alternativos se ha incluido la variable área territorial. Como se verá más adelante, esta variable recoge en parte la omisión de la variable de reservas minerales.

\subsection{Dotación de factores alternativos}

Los resultados obtenidos en las tres estimaciones (denominadas de corte transversal, porque se ha considerado datos por países a lo largo del tiempo, o cross-country) indican que la dotación de factores alternativos tiene mayor presencia en comparación con los factores tradicionales.

Entre las variables que más destacan dentro de este grupo se encuentra la variable grado de apertura (TRADE), definida como la participación del comercio total (exportaciones + importaciones) sobre el PBI. Ésta se encuentra presente en tres de las cuatro relaciones estimadas por tipo de datos (excepto en la estimación de las exportaciones de bienes intensivos en capital humano).

Los resultados indican que su presencia afecta la participación de las exportaciones de productos intensivos en recursos naturales. Como es sabido, el comercio de este tipo de bienes puede desarrollarse aun con bajos niveles de apertura comercial (por ser commodities y no es- tar sujetos a demasiadas trabas arancelarias y paraarancelarias). Luego, el inicio de procesos de apertura comercial favorece en mayor magnitud las exportaciones de otros tipos de productos, reduciendo la participación de los bienes intensivos en recursos naturales. Dentro del APEC, se puede encontrar al Perú como uno de los países con mayor dependencia de las exportaciones de este tipo de productos $(85,1 \%$ en promedio) $\mathrm{y}$, a la vez, con menor grado de apertura $(30 \%)$. Asimismo, e invirtiendo el sentido causaefecto en la relación estimada, se puede inferir que precisamente aquellos países que han contado con mayor disponibilidad de recursos han tendido a abrirse con mayor prontitud al comercio exterior. Dentro de este último grupo de países se cuenta Singapur (apertura comercial promedio de $343 \%$ ) y Hong Kong (apertura de $242 \%$ ), con participaciones de $28,1 \%$ y $8,4 \%$, respectivamente.

Las estimaciones de las ecuaciones 2 y 3 del cuadro 4 del apéndice $C$ en cada una de las tres estimaciones pool data indican que la variable apertura permite incrementar la participación de las exportaciones de productos intensivos en mano de obra no calificada y las exportaciones de productos intensivos en tecnología. Ejemplo del primero de este tipo de relación lo constituyen Hong Kong, Taiwan y Tailandia. En cambio, Singapur y Malasia estarían indicando que la apertura comercial es beneficiosa para las exportaciones tecnológicas.

El gráfico 5 muestra la participación de las exportaciones de productos intensivos en recursos naturales y en tecnología para los países del APEC. En este gráfico se ha dispuesto más cerca al eje «Y» a aquellos países con mayor apertura co- 
mercial, en tanto que los menos abiertos comercialmente se encuentran más alejados de este eje. Se puede observar que aquellos países con menor grado de apertura presentan mayor dependencia de los productos intensivos en recursos naturales (como Nueva Zelanda, Chile, Indonesia, México, Australia y Perú). En tanto aquellos países con mayor grado de apertura, como Hong Kong, Taiwan y Corea, presentan mayor dependencia de las exportaciones de productos intensivos en mano de obra no calificada.

La variable proxy de dotación educacional, promedio de años de estudios de la población adulta de 25 o más años de edad (School), genera un afecto negativo en la participación de las exportaciones de productos intensivos en recursos naturales y un efecto positivo en las exportaciones de productos intensivos en mano de obra no calificada. En el primer caso, la explicación es relativamente obvia: paí- ses con poblaciones altamente educadas no cuentan con mano de obra para actividades como la agricultura o pesquería. Por otro lado, hay países como Papua Nueva Guinea e Indonesia que registran bajísimos niveles de educación y que dependen, en gran medida, de este tipo de exportaciones.

Luego, la presencia de este factor con signo positivo en las exportaciones de productos intensivos en mano de obra es contraria a lo esperado, sobre todo cuando en la muestra hay países que, como Estados Unidos, Nueva Zelanda, Canadá y Australia, cuentan con población con alto número de años de estudios y, a la vez, con una baja participación de este tipo de exportaciones. Sin embargo, hay que considerar que países como Hong Kong y Corea también cuentan con población de alto número de años de estudios y, a la vez, elevada participación de este tipo de exportaciones. Probablemente estos elemen-

\section{Gráfico 5}

Participación de las exportaciones intensivas en recursos naturales y mano de obra no calificada (como \% del total de las exportaciones)

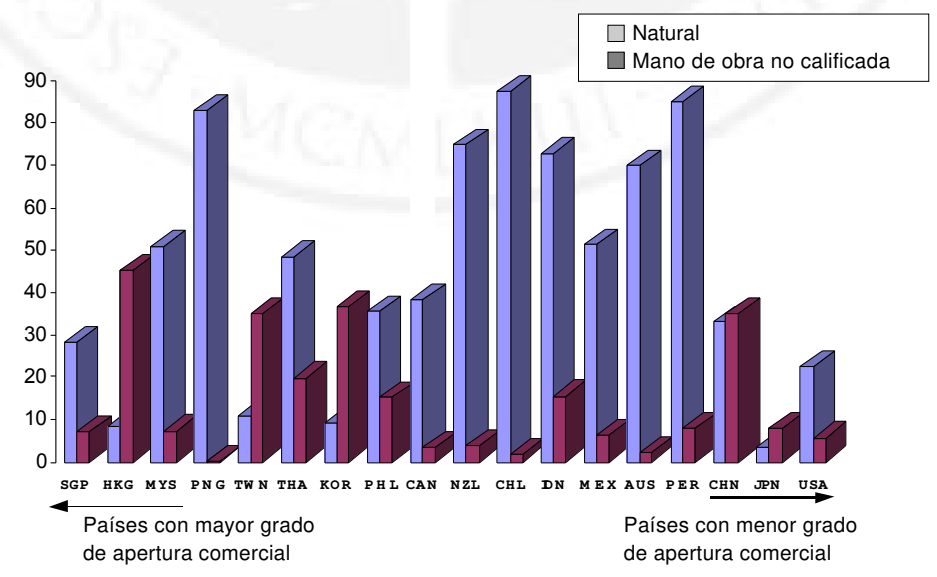

Año 8, n.ำ 14, junio de 2003 
tos han permitido que las estimaciones presenten un signo positivo para esta variable.

La variable GDP per cápita (GDP) se encuentra presente en las exportaciones de productos intensivos en capital humano para las tres estimaciones efectuadas. Como era de esperarse, países más ricos tienen mayores exportaciones en este tipo de productos. Entre los países que ejemplifican esta relación se encuentran Estados Unidos, Canadá y Japón. Todos ellos son países con elevados ingresos per cápita y alta participación en este tipo de exportaciones. El único país que no cumple de manera clara esta relación es Australia, país que cuenta con ingresos per cápita superiores a Japón (Japón registra un ingreso per cápita de 13,5 mil dólares frente a 14,6 mil dólares de Australia), pero con una participación relativa mucho más baja (la participación de este tipo de productos llega a $42,5 \%$ para el caso de Japón, mientras en Australia es de sólo $5,8 \%$ ). Perú ocupa el puesto decimocuarto (de 18 países) en lo referido al ingreso per cápita (de 2,6 mil dólares) y con una participación de $2,6 \%$ de productos intensivos en capital humano, lo cual lo ubica en la posición penúltima, luego de Filipinas y antes de Papua Nueva Guinea.

La presencia de esta variable en la ecuación de productos intensivos en mano de obra no calificada no lleva el signo esperado, ya que los países con mayor nivel de ingresos no cuentan con ventajas competitivas en lo referente a mano de obra no calificada.

Los efectos que genera la variable población de cada país (POP) son positivos para las exportaciones de productos intensivos en mano de obra no calificada, para los intensivos en tecnología y para los intensivos en capital humano.

En lo referente al primer tipo de exportaciones, China constituye un caso representativo. Este país cuenta con una población de más de mil millones de personas, a la vez que registra una de las mayores dependencias de este tipo de exportaciones (aproximadamente 35\%). Luego, la relación directa entre esta variable y la participación de las exportaciones intensivas en el uso de tecnología está sustentada por la presencia de países como Estados Unidos y Japón, entre los más importantes. Al parecer, los efectos generados por estos países estarían superando a los que están produciendo China e Indonesia, los cuales tienen una elevada población pero poca participación en productos tecnológicos.

Finalmente, las exportaciones intensivas de capital humano estarían contando con la población como variable explicativa. Sin embargo, esta población requiere ser calificada. Éste es el caso de Japón, país que presenta una elevada participación (de 42,5\%) en este tipo de producto y cuenta con una población considerable. En el otro extremo de la muestra está Papua Nueva Guinea, país cuya participación de este tipo de productos es de apenas el $0,3 \%$ y dentro de la muestra es uno de los que cuenta con menor población.

Adicionalmente, las estimaciones efectuadas indican que la variable POP repercute negativamente sobre la participación de las exportaciones de los productos intensivos en recursos naturales. Sin embargo, se esperaría que esta variable no fuese significativa para esta ecuación. Al parecer, la presencia de países como Japón, Estados Unidos y China, con eleva- 
das poblaciones y baja participación en este tipo de exportación, estarían generando estos resultados.

En lo que respecta a la variable área geográfica (AREA), se observa que ésta repercute positivamente en las exportaciones de productos intensivos en recursos naturales y negativamente en las exportaciones de productos intensivos en tecnología e intensivos en capital humano.

En el primer caso, se esperaría que países con extensas áreas geográficas cuenten con mayor cantidad y variedad de recursos naturales, y viceversa. En este caso, se debe considerar que en la muestra hay países con áreas territoriales muy reducidas, como Hong Kong, Singapur y Taiwan (los dos primeros con tan sólo mil kilómetros cuadrados y el tercero con 36 mil kilómetros cuadrados), que a la vez presentan baja participación de este tipo de productos $(8 \%, 28 \%$ y $11 \%$, respectivamente).

Luego, con relación a los efectos negativos del tamaño geográfico de un país sobre los recursos tecnológicos, se puede considerar que esta característica reduce la participación de este tipo de exportaciones, debido a que favorece a otros sectores (como al primario, mencionado anteriormente). Considerando la figura inversa, se puede considerar que países que siempre han contado con la restricción de límites territoriales estrechos han buscado desarrollar sus ventajas en campos en donde la extensión territorial no fuese una limitación, tal como lo son la tecnología y la inversión en el capital humano. Entre estos países se encuentran Singapur y Hong Kong (ver gráfico 6).

A su vez, la relación negativa entre participación de exportaciones intensivas

Gráfico 6

Relación entre el área territorial y la participación de las exportaciones intensivas en tecnología

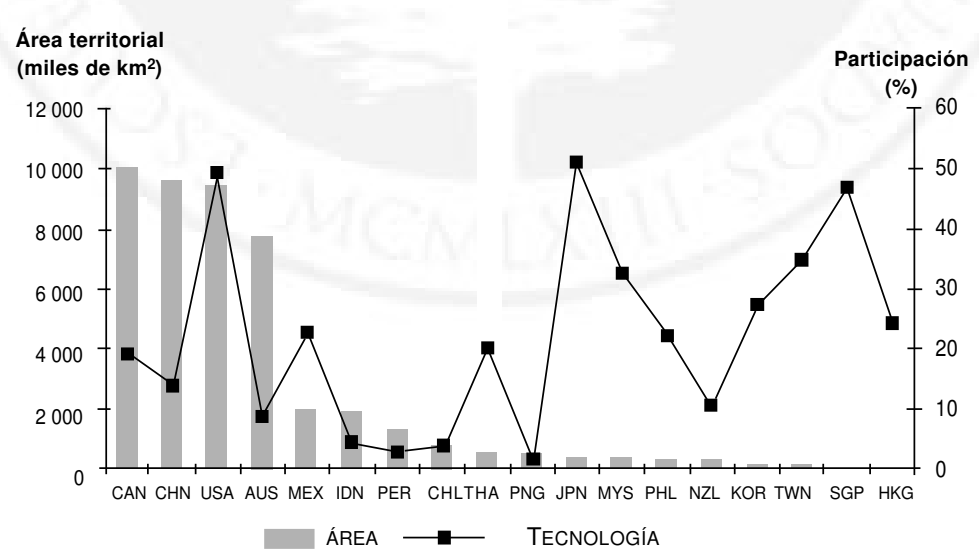

Fuente: PC-TAS y APEC: Aspects of Market Integration in APEC: Trade, Foreign Direct Investment and Labor Migration (1999). 
en capital humano y área territorial estaría reflejando que países con mayor extensión territorial podrían verse sesgados a la exportación de productos intensivos en recursos naturales. En los casos puntuales, se observa que entre aquellos países que cuentan con baja participación en el total de este tipo de exportaciones y grandes extensiones territoriales se encuentran Australia y China.

Finalmente, cabe indicar que la variable relativa al grado de sobrevaluación real resultó no ser significativa en ninguna de las ecuaciones, de lo cual se puede deducir que el efecto precio relativo no sería un factor que influya sobre algún tipo de sector en especial. Este resultado constituye una prueba empírica en contra de la creencia de que el factor precio relativo afecta más a productos más «sensibles», como los intensivos en mano de obra no calificada en comparación con los productos intensivos en recursos naturales (como las exportaciones mineras). En realidad, no tendría efecto sobre tipo alguno de exportaciones.

\section{Conclusiones}

1. Los datos recogidos muestran que los países en desarrollo miembros del APEC no han logrado, en general, disminuir significativamente su dependencia de la exportación de productos intensivos en recursos primarios. Sin embargo, el caso peruano muestra un incremento significativo de la participación de las exportaciones de productos intensivos en mano de obra no calificada. No obstante, las exportaciones intensivas en recursos primarios mantienen su predominio con respecto a las exportaciones totales.
2. La teoría neoclásica del comercio internacional provee una explicación a este fenómeno, debido a que sus principales postulados predicen que los países tienden a exportar aquellos productos intensivos en el factor que poseen en abundancia relativa.

3. Las regresiones efectuadas a diversas muestras de corte transversal correspondientes a datos de los países del APEC muestran que, en efecto, las variables de dotaciones relativas de factores son significativas para explicar la proporción de los productos exportados intensivos en determinados factores. En particular, la variable $\mathrm{ca}$ pital por trabajador es significativa en las estimaciones que explican la participación de las exportaciones de tecnología (generando un efecto positivo) y la participación de las exportaciones de bienes intensivos en mano de obra no calificada (efecto negativo).

4. Asimismo, la variable población favorece las exportaciones de productos intensivos en mano de obra no calificada, tecnología y capital humano. Por otro lado, la variable área geográfica incrementa la participación de las exportaciones de bienes intensivos en recursos naturales.

5. Sin embargo, hay otras variables que también son significativas en las distintas regresiones y que podrían ser afectadas a través de las políticas adecuadas. La primera y más importante entre ellas es el grado de apertura. Esta variable afecta negativamente la participación de los productos intensivos en recursos naturales en el total de exportaciones, y positivamente la participación de los productos intensivos 
en mano de obra y tecnología. Aparentemente, la oferta de los primeros sería inelástica, y las mayores posibilidades de comercio se verían traducidas en incrementos de la exportación de bienes manufacturados con un mayor valor agregado.

6. De igual manera, la variable proxy de dotación educacional genera un efecto negativo en la participación de productos intensivos en recursos natura- les, y positivo en la participación de productos intensivos en mano de obra. $\mathrm{Al}$ respecto, mayor número de años de estudios tendría un impacto cualitativo sobre el factor trabajo e incrementaría su productividad. Dichos incrementos en la productividad actuarían en la práctica como un incremento del factor trabajo y, por lo tanto, en un incremento de los productos intensivos en el mismo, con el efecto adicional de salarios más altos por trabajador. 


\section{Referencias bibliográficas}

ARMINGTON, Paul S. 1969. A Theory of Demand for Products Distinguished by Place of Production. International Monetary Fund Staff Papers. Vol. 16, n. ${ }^{\circ}$, págs. 159-178.

APEC ECONOMIC COMMITTEE. 1999. Aspects of Market Integration in APEC: Trade, Foreign Direct Investment and Labor Migration. Febrero.

- 1999. Assesing APEC Trade Liberalization and Facilitation - 1999 Update. Singapore: APEC Secretariat.

1999. 1999 APEC Economic Outlook Singapore: APEC Secretariat.

1996. 1996 APEC Economic Outlook. Singapore: APEC Secretariat.

BANCO CENTRAL DE RESERVA DEL PERÚ. 1999. Memoria 1999. Lima: BCRP.

— 2000. Memoria 2000. Lima: BCRP.

—. 2001. Memoria 2001. Lima: BCRP.

BARRO, Roberto J. y LEE, Jong-Wha. 2000. International Data on Educational Attainment: Updates and Implications. CID Working Paper n. ${ }^{\circ}$ 42. Human Capital Updated Files (April).

CHENG, Leonard K. y FAI LEUNG, Siu. 1999. Aspect of Market Integration in: APEC: Trade, Foreign Direct Investment and Labor Migration. Singapore: APEC Secretariat.

\section{COMISIÓN ECONÓMICA PARA AMÉRICA} LATINA Y EL CARIBE. 2000. Crecer con estabilidad: el financiamiento del desarrollo en el nuevo contexto internacional. Santiago de Chile: Cepal.

DE FERRANTI, David; PERRY, Guillermo; LEDERMAN, Daniel y MALONEY, William. 2002. From Natural Resources to the Knowledge Economy: Trade and Job Quality. Washington, D.C.: The World Bank.

DEARDORF, Alan V. 1994. Exploring the Limits of Comparative Advantage. Weltwirtschaftliches Archiv. Vol. 130, n. ${ }^{\circ}$ 1, págs. 1-18.

GROSSMAN, Gene M. y HELPMAN, Elhanan. 1991. Innovation and Growth in the Global Economy. Cambridge, Massachusetts: MIT Press.

HARRIGAN, James. 1997. Technology, Factor Supplies, and International Specialization: Estimating the Neoclassical Model. The American Economic Review. Vol. 87, n. ${ }^{\circ}$, págs. 475-494.

1995. Factor Endowments and the International Location of Production: Econometric Evidence for the OECD, 19701985. Journal of International Economics. Vol. 39, págs. 123-141.

HARRISON, Ann y HANSON, Gordon. 1999. Who Gains from Trade Reform? Some Remaining Puzzles. Journal of Development Economics. Vol. 59, págs. 125-154. 
HESTON, Alan y SUMMERS, Robert. 1991. The Penn World Table (Mark 5): An Expanded Set of International Comparisons, 1950-1988. Quarterly Journal of Economics, May., págs. 327-368.

KRAUSE, Lawrence B. 1982. U.S. Economic Policy toward the Association of Southeast Asian Nations. Washington, D.C.: Brookings Institution.

LEAMER, Edward E. 1984. Sources of International Comparative Advantage: Theory and Evidence. Cambridge, MA: The MIT Press.
LEAMER, Edward E.; MAUL, Hugo; RODRÍGUEZ, Sergio y SCHOTT, Peter K. 1999. Does Natural Resource Abundance Increase Latin American Income Inequality? Journal of Development Economics. Vol. 59, págs. 3-42.

TREFLER, Daniel. 1995. The Case of the Missing Trade and Other Mysteries. American Economic Review. Vol. 85, n. ${ }^{\circ}$ 5, págs. 1029-1046.

WOOD, Adrian. 1994. Give Heckscher and Ohlin a Chance! Weltwirtschaftliches Archiv. Vol. 130, n. ${ }^{\circ}$ 1, págs. 20-48. 
Apéndice A:

Clasificación Uniforme del Comercio Internacional

(Revisión 2)

\begin{tabular}{|c|c|}
\hline Producto & CUCI Rev. 2 \\
\hline $\begin{array}{l}\text { Productos intensivos en recursos naturales } \\
\text { Food and live animals, chiefly for food } \\
\text { Beverages and tobacco } \\
\text { Beverages } \\
\text { Tobacco } \\
\text { Crude materials, except fuel } \\
\text { Mineral Fuels, lubricants, and related materials } \\
\text { Coal } \\
\text { Cruel petroleum and petroleum products } \\
\text { Gas, natural and manufactured } \\
\text { Electric current } \\
\text { Animal and vegetable oils } \\
\text { Manufactured goods classified chiefly by material } \\
\text { Leather } \\
\text { Cork and wood manufactures } \\
\text { Mineral manufactures } \\
\text { Pearls, precious and semi-precious stones } \\
\text { Pig iron } \\
\text { Nonferrous metals }\end{array}$ & 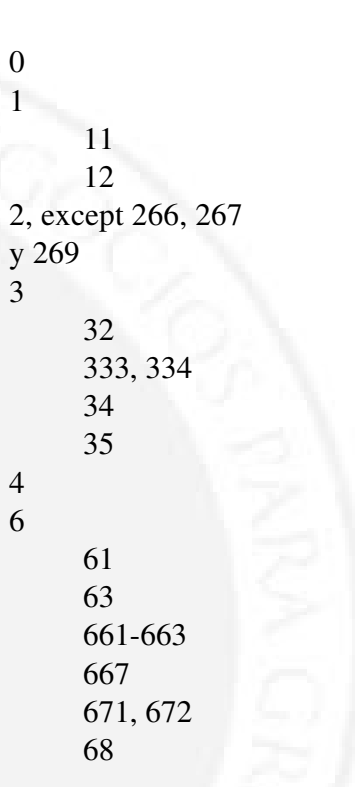 \\
\hline $\begin{array}{l}\text { Productos intensivos en mano de obra no calificada } \\
\text { Manufactured goods classified chiefly } \\
\text { by material } \\
\text { Textile yarn, fabrics, and textiles products } \\
\text { Glass and pottery } \\
\text { Machinery and transport equipment } \\
\text { Ships } \\
\text { Mis. Manufactured goods } \\
\text { Furniture } \\
\text { Clothing } \\
\text { Footwear } \\
\text { Mis. Consumer goods } \\
\text { Toys } \\
\text { Commodities not classified by kind } \\
\text { Armoured vehicles and firearms }\end{array}$ & $\begin{array}{ll}6 & \\
& 651-657 \\
& 664-666 \\
7 & \\
& 793 \\
8 & \\
& 82 \\
& 84 \\
& 85 \\
& 81,83,893,895,899 \\
& 894 \\
9 & \\
& 951\end{array}$ \\
\hline $\begin{array}{l}\text { Productos intensivos en tecnología } \\
\text { Chemicals and related products, n.e.s. } \\
\text { Machinery and transport equipment }\end{array}$ & $\begin{array}{l}5 \text {, except } 53 \text { and } 55 \\
7\end{array}$ \\
\hline
\end{tabular}


(Continúa Productos intensivos en tecnología Open)

Power generating machinery and equipment

Machinery specialized for particular industries

Metal working machinery

General industrial machinery and equipment

Office machines and auto, data processing equip

Telecommunications equipment and parts

Electrical machinery, apparatus, and appliances Aircraft

Mis. Manufactured goods

Scientific instrument Optical equipment

\section{Productos intensivos en capital humano}

Chemicals and related products, n.e.s.

Dyes and paints

Perfumes and cleaning materials

Manufactured goods classified chiefly by material Rubber

Paper

Steel

Manufactures of metals

Machinery and transport equipment

Non-electrical machines, tools, and parts

Television

Radio

Household electrical and non-electrical apparatus Road vehicles

Trains

Mis. Manufactured goods

Watches and clocks

Printed matters

Jewelry

Musical instruments

\section{7}

881-884

5

53

55

6

62

64

673-679

69

7

745,749

761

762

775

78

791

8

885

892

896,897

898 


\section{Apéndice B: \\ Modelo Hecksher-Ohlin ampliado}

En esta parte del trabajo se procede a explicar el marco teórico que sustenta el análisis estadístico efectuado en la sección 4, el mismo que, en términos generales, busca relacionar las exportaciones (netas) con las dotaciones de factores productivos. Este modelo es recogido del trabajo realizado por Leamer (1984).

\section{A. Modelo base}

El modelo básico con el cual Leamer (1984) inicia su análisis descansa sobre la base del teorema de Hecksher-Ohlin, el cual señala que un país con comercio internacional equilibrado exportará el producto que use intensivamente aquel factor relativamente abundante en su territorio e importará aquel producto que incorpore mayoritariamente el factor relativamente más escaso.

De este modo, y asumiendo tecnología del tipo Leontieff, Leamer plantea el siguiente sistema de ecuaciones que relaciona la oferta de factores productivos con sus respectivas demandas:

$$
\begin{aligned}
& \text { (1) } K=a_{K 1} Y_{1}+a_{K 2} Y_{2} \\
& \text { (2) } L=a_{L 1} Y_{1}+a_{L 2} Y_{2}
\end{aligned}
$$

en donde $K$ y $L$ representan las cantidades de los dos factores productivos (capital y trabajo) disponibles en un país; $Y_{j}(\mathrm{j}=1,2)$ denota la cantidad producida en el país de dos productos y $a_{i j}(\mathrm{i}=\mathrm{K}, \mathrm{L} ; \mathrm{j}=1,2)$ indica los requerimientos de cada factor para la producción de una unidad de producto. Estos coeficientes se encuentran determinados por la tecnología disponible en cada sector.

De esta manera, las ecuaciones (1) y (2) representan un sistema que puede resolverse para los productos $\mathrm{Y}$ en función de los insumos K, L y de las intensidades de los factores.
En notación matricial, este arreglo puede generalizarse en un modelo con múltiples productos y factores de producción, con la condición de que estos últimos no excedan al número de productos, o que el modelo esté identificado o subidentificado. Luego:

$$
\text { (3) } Y=A^{-1} V
$$

donde $Y$ es que el vector de productos y $V$ es el vector de dotación de factores. $A$ es el vector de las intensidades de cada factor, el cual es invertible en tanto que las tecnologías sean diferentes entre sectores (por lo que los ratios de las intensidades por factor son diferentes entre los sectores).

Generalizando la ecuación (3), la producción de la economía mundial puede escribirse en conjunto de la misma forma:

$$
\text { (4) } Y_{W}=A^{-1} V_{W}
$$

Luego, asumiendo que los países consumen cada producto en las mismas proporciones, el vector del consumo por país puede expresarse como:

$$
\text { (5) } \quad C=s Y_{W}
$$

donde $Y w$ es el vector de producción mundial y $s$ es la proporción de la producción mundial consumida por cada país*.

Así, pues, el vector de exportaciones es el producto de la inversa del vector de intensidades de factores por la diferencia entre el vector de dotaciones de cada país y el vector

* El supuesto del consumo proporcional es poco realista y es usado sólo por simplicidad, pero no forma una parte fundamental de este argumento. Más adelante se discuten las desviaciones a este supuesto. 
de dotaciones del mundo. Esto, claro está, después de considerar el hecho de que las exportaciones netas son la diferencia entre la producción doméstica y el consumo:

$$
\text { (6) } N X=Y-C=A^{-1}\left(V-s V_{W}\right)
$$

El vector invertido $A$ contiene las intensidades de los factores por tipo de productos, mas no relativos a las diferencias entre países. Sin embargo, debido a que la proporción del consumo de cada país (relativo al mundo) es un promedio ponderado de la proporción de sus propios factores (también relativo a las dotaciones del mundo), se tiene que $s$ puede representarse de la siguiente manera:

$$
\begin{aligned}
& K / K_{W}>s>L / L_{W}, \text { o, } \\
& K / K_{W}<s<L / L_{W}
\end{aligned}
$$

Entonces, un país con abundante capital, tendrá: $K / K_{W}>s>L / L_{W}$; mientras que un país con abundante mano de obra tendrá: $K / K_{W}<s<L / L_{W}$

\section{B. Las extensiones}

Con el objetivo de hacer más realista al modelo básico planteado líneas arriba se procede a tomar en cuenta algunos temas. El primero de ellos hace referencia a la movilidad de los factores y cómo este criterio debería guiar el diseño de la versión empírica del modelo planteado en la ecuación (6).

En este sentido, se considera que la dotación de factores perfectamente móviles no debería afectar la estructura de las exportaciones, sino que ésta se encuentra determinada por la abundancia doméstica de los factores inmóviles y por el precio internacional relativo de estos factores. Bajo este razonamiento Wood (1994), señala que los modelos crosscountry no deberían incluir el stock de capital doméstico. Sin embargo, la idea de que el capital es un factor completamente móvil se encuentra en debate, y lo destacable de este punto es que la noción de movilidad debe considerarse en el diseño de los modelos de comercio.

Otro tema hace referencia a la condición de «comercio balanceado» que se encuentra implícitamente en la ecuación (6). Según Deardorff (1994), el empleo de datos anuales permite fácilmente contar con periodos en donde no se mantenga esta condición. Sin embargo, según este autor, el modelo puede seguir siendo válido si se considera un horizonte multiperiódico en donde al final del mismo se cumpla con la condición de comercio balanceado. No obstante, queda la inquietud acerca de que si esta flexibilización para periodos puntuales pueda llevar a situaciones de inconsistencia del modelo HOV. Para entender mejor esta última situación se presenta la figura 1. En ella se observa una primera situación (denotada por los puntos de consumo, $C_{B T}$, y de producción, $Y_{T}$. Ambos puntos se encuentran sobre la misma recta de precios relativos, lo cual indica la existencia de una igualdad de comercio equilibrado. Ahora se considera un nuevo punto de consumo $C_{U T}$, en el cual se tiene menos cantidad de exportaciones del bien $Y_{1}$ e $Y_{2}$ (o bien, mayor importaciones en el caso de $Y_{1}$ ). Esta nueva situación estaría reflejando un déficit comercial. Luego, la pregunta por responder sería la siguiente:

¿Es posible que los factores que han guiado a una situación de déficit comercial puedan incluso reducir las exportaciones del bien $Y_{2}$ a tal punto en que éstas se conviertan en negativas ( $\mathrm{y}$, por consiguiente, se genere una situación de inconsistencia del teorema de HOV)?

En lo que respecta a la construcción de nuestro modelo empírico, esta discusión indica claramente que es necesaria la inclusión de factores que determinen la absorción de productos transables, incluyendo los precios relativos de los bienes transables y no transables, ya que éstos claramente afectan el valor observado de las exportaciones netas.

Una tercera consideración que se tendrá presente al momento de efectuar las estima- 
Figura 1

Las exportaciones netas y el supuesto de comercio equilibrado

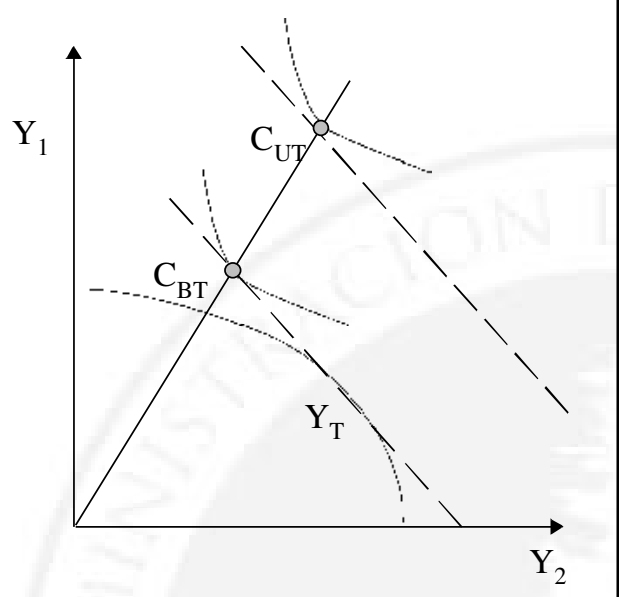

ciones del modelo cross-country es la inclusión de variables relativas al nivel de ingreso. Ello debido a que los montos de las exportaciones netas pueden ser afectados por este tipo de variable si se considera que el consumidor no presenta curvas de indiferencias homotéticas. Es decir, si uno de los bienes en mención es considerado como bien superior o si existe algún tipo de sesgo a consumir bienes nacionales a medida que el ingreso se incrementa (este supuesto fue sustentado por Armington 1969). El primero de estos dos casos es representado en la figura 2.

En ella se muestran dos fronteras de posibilidades de producción. Como es de esperarse, aquella que se encuentra más cercana al origen representa un estado de determinada economía que cuenta con reducidos recursos. Luego, se asume que existe un shock positivo que permite que esta frontera se expanda (o bien, esta figura puede representar una comparación estática entre una nación rica y un país pobre). Los dos rayos que parten del origen representan la senda de consumo y producción ante la expansión del ingreso (el rayo que va a través de los puntos $Y_{a}$ e $Y_{b}$ es el camino de la producción; en tanto que el que corre a través de los puntos de consumo $C_{B T}$ y $C_{b}$ corresponde al camino del consumo).

$C_{b}$ es el punto de consumo de la economía más rica, si es que la composición del consumo no dependiese del nivel de ingreso. Cuando la composición de consumo efectivamente depende del nivel de ingreso (es decir, se está considerando la existencia de algún bien superior o inferior), el punto de consumo más elevado no necesariamente sería $C_{b}$, ya que éste podría ser un punto como $C_{d}$ de la figura 2. La curva que corre a través de los puntos $C_{B T}$ y $C_{d}$ es el camino que sigue la expansión del consumo para el caso donde $Y_{1}$ es un bien superior. Es decir, el punto de consumo $C_{d}$ es el punto de tangencia entre la línea de precios relativos constantes y la curva de indiferencia que tiende a favor del consumo de $Y_{1}$, en relación con la curva de indiferencia que corre desde el punto de bajo consumo $C_{B T}$. El principal resultado de este simple análisis es que las exportaciones netas del bien inferior $Y_{2}$ son más altas y las exportaciones netas del bien superior $Y_{1}$ son menores que las esperadas bajo el supuesto de preferencias homotéticas. Similar análisis se efectúa en el caso de considerar la existencia de preferencias por el consumo nacional (aunque en este caso la senda de expansión tendería a doblar hacia $\mathrm{Y}_{2}$ dado que es el producto nacional (no se importa). Bajo esta justificación, los modelos empíricos estimados en las siguientes secciones consideran variables como el ingreso per cápita.

Las barreras arancelarias y los costos de transportes también presentan desviaciones relevantes del modelo de HOV normal. Según Leamer (1984), este impedimento al libre movimiento de bienes se refleja a través de las discrepancias entre los precios domésticos y los precios internacionales. Por este motivo, teóricamente se debería de considerar los precios domésticos de las dotaciones y de las 
Figura 2

Preferencias no-homotéticas y las exportaciones netas

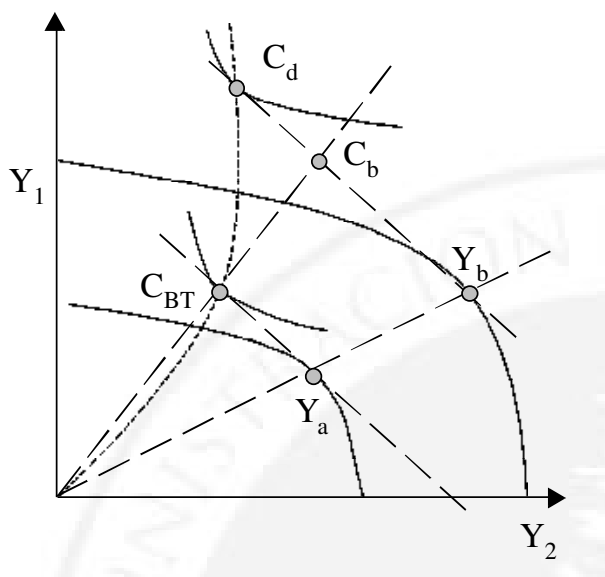

exportaciones netas, en tanto que las dotaciones mundiales deberían ser evaluadas a precios internacionales. Sin embargo, este procedimiento en la práctica es casi imposible de implementar cuando se considera una muestra mediana de países. Un procedimiento de seguridad contra dicho efecto implica la eliminación de «outliers» en la muestra en la que se está trabajando.

Aparte de los factores mencionados anteriormente, existen otros criterios que si bien no serán incorporados en las subsiguientes estimaciones (principalmente por escasez de información), son mencionados a continuación, por constituir puntos de debate en la actualidad:

- La tecnología y habilidades. Éstos han sido elementos importantes en la literatura y teoría empírica relativa a los los determinantes del comercio desde los años 90.
Trefler (1995) mostró que una versión extendida del modelo-HOV que incluye tanto las diferencias tecnológicas entre países desarrollados y en desarrollo así como el «sesgo al consumo nacional» (del tipo Armington) funciona empíricamente mejor que el modelo HOV simple, así como el modelo expandido HOV con el comercio desequilibrado. Grossman y Helpman (1991) dan énfasis al papel del conocimiento patentado, el cual actúa como una dotación de la producción que no es transferible por los países. Sin embargo, en la práctica, las diferencias entre los países en cuanto a tecnología y «know-how» son difíciles de medir.

- Otro supuesto limitante del modelo HOV básico se refiere a la presunta relación lineal entre el exceso de las dotaciones de factores y la estructura de exportaciones netas. Esta relación se deriva del supuesto de que todos los países producen todos los bienes posibles, pero éste debería ser flexibilizado, ya que muchos países, sobre todo los en desarrollo, no producen ciertos bienes.

- Un problema importante que afecta la inferencia de resultados empíricos pero no la interpretación de la teoría básica es la presencia de factores de producción especializados (Leamer 1984). Desde que ciertos factores, sobre todo la tierra, pero también el equipamiento del capital especializado y las habilidades en el trabajo, no pueden transferirse fácilmente o no pueden adaptarse para la producción de otro tipo de bienes, entonces, el modelo básico debe ser corregido. 
Apéndice C:

Datos diversos y resultados de estimaciones

\section{Cuadro 1}

Apertura comercial en los países miembros de APEC

(Exportaciones + importaciones)/ PBI

\begin{tabular}{|l|r|r|r|}
\hline País & $\mathbf{1 9 9 0}$ & $\mathbf{1 9 9 9}$ & Incremento \\
\hline Desarrollados & 34 & 40 & $18 \%$ \\
Australia & 52 & 84 & $62 \%$ \\
Canadá & 21 & 19 & $-7 \%$ \\
Japón & 55 & 87 & $60 \%$ \\
Nueva Zelanda & 21 & 25 & $19 \%$ \\
Estados Unidos & & & \\
& & & \\
En desarrollo & 66 & 56 & $-15 \%$ \\
Chile & 27 & 41 & $54 \%$ \\
China & 61 & 101 & $67 \%$ \\
Filipinas & 260 & 261 & $0 \%$ \\
Hong Kong & 50 & 62 & $24 \%$ \\
Indonesia & 60 & 77 & $29 \%$ \\
Corea del Sur & 151 & 218 & $45 \%$ \\
Malaysia & 38 & 63 & $64 \%$ \\
México & 90 & 87 & $-3 \%$ \\
Papúa Nueva Guinea & 24 & 32 & $35 \%$ \\
Perú & 36 & 50 & $39 \%$ \\
Rusia & 386 & 293 & $-24 \%$ \\
Singapur & 76 & 102 & $35 \%$ \\
Tailandia & 88 & 93 & $5 \%$ \\
Taiwan & 60 & 109 & $83 \%$ \\
Vietnam & & & \\
\hline & & & \\
\hline
\end{tabular}

Fuente: FMI, Estadísticas Financieras Internacionales. 
Cuadro 2

Crecimiento de las exportaciones de los países del APEC: 1990-1999 (en variación porcentual)

\begin{tabular}{|c|c|c|c|c|c|}
\hline País & $\begin{array}{c}\text { Intensivos } \\
\text { recursos } \\
\text { naturales }\end{array}$ & $\begin{array}{l}\text { Intensivc } \\
\text { en trabaj }\end{array}$ & $\begin{array}{c}\text { Intensivos } \\
\text { en tecnología }\end{array}$ & $\begin{array}{c}\text { Intensivos } \\
\text { en capital } \\
\text { humano }\end{array}$ & $\begin{array}{c}\text { Exportaciones } \\
\text { totales }\end{array}$ \\
\hline \multicolumn{6}{|l|}{ Desarrollados } \\
\hline Australia & 52 & 131 & 73 & 72 & 28 \\
\hline Canadá & 49 & 245 & 110 & 102 & 90 \\
\hline Japón & 48 & 47 & 46 & 12 & 112 \\
\hline Nueva Zelanda & 22 & 57 & 93 & 29 & 32 \\
\hline Estados Unidos & 10 & 99 & 99 & 79 & 76 \\
\hline \multicolumn{6}{|l|}{ En desarrollo } \\
\hline Brunei & -10 & 650 & 164 & 151 & $1 *$ \\
\hline Chile & 73 & 148 & 219 & 250 & 85 \\
\hline China & 44 & 235 & 617 & 128 & 199 \\
\hline Filipinas & -6 & 75 & 799 & 322 & 319 \\
\hline Hong Kong & -33 & 77 & 1797 & 3 & 55 \\
\hline Indonesia & 25 & 97 & 763 & 423 & 80 \\
\hline Corea del Sur & 155 & 9 & 246 & 97 & 116 \\
\hline Malaysia & 22 & 114 & 424 & 145 & 176 \\
\hline México & 38 & 1346 & 934 & 669 & 396 \\
\hline Papúa Nueva Guinea & 87 & -66 & 26 & -37 & 66 \\
\hline Perú & 88 & 66 & 93 & 38 & 85 \\
\hline Singapur & -4 & 10 & 215 & 36 & 114 \\
\hline Tailandia & 53 & 48 & 405 & 200 & 146 \\
\hline Taiwan & 92 & 65 & 191 & 123 & 132 \\
\hline
\end{tabular}

*Periodo 1990-1997

Fuente: World Trade Database 1980-1995, PC-TAS 1995-1999. 


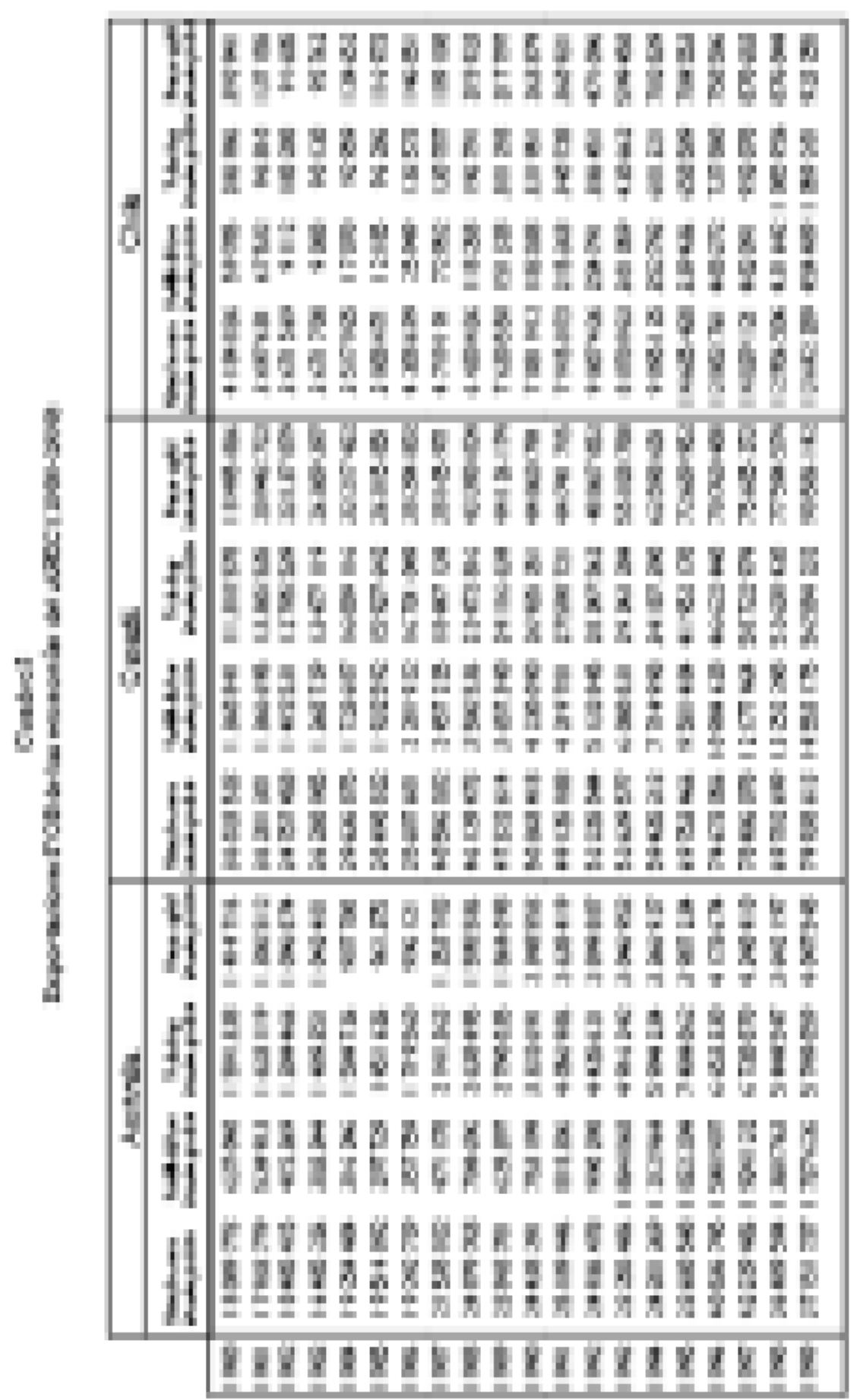




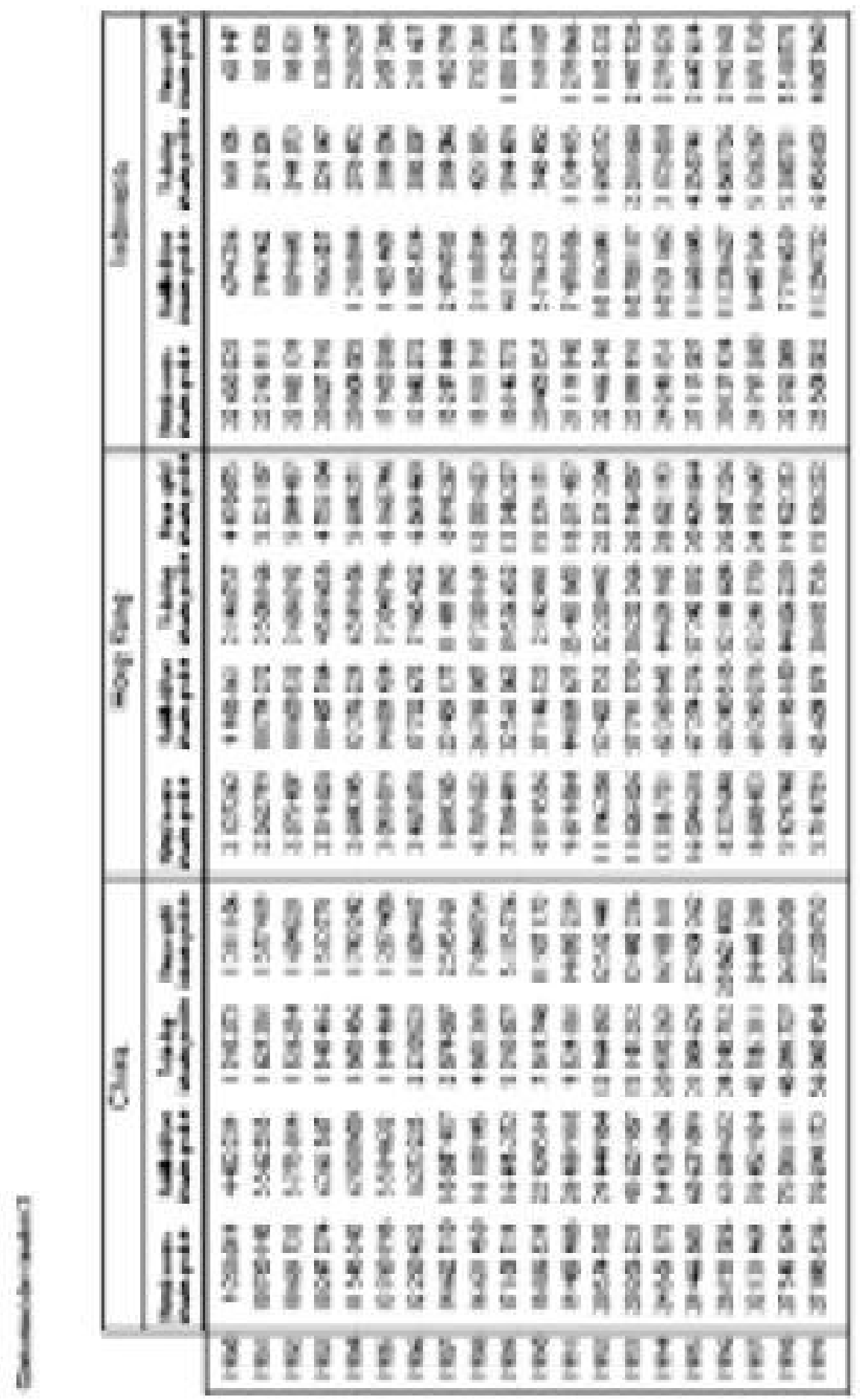




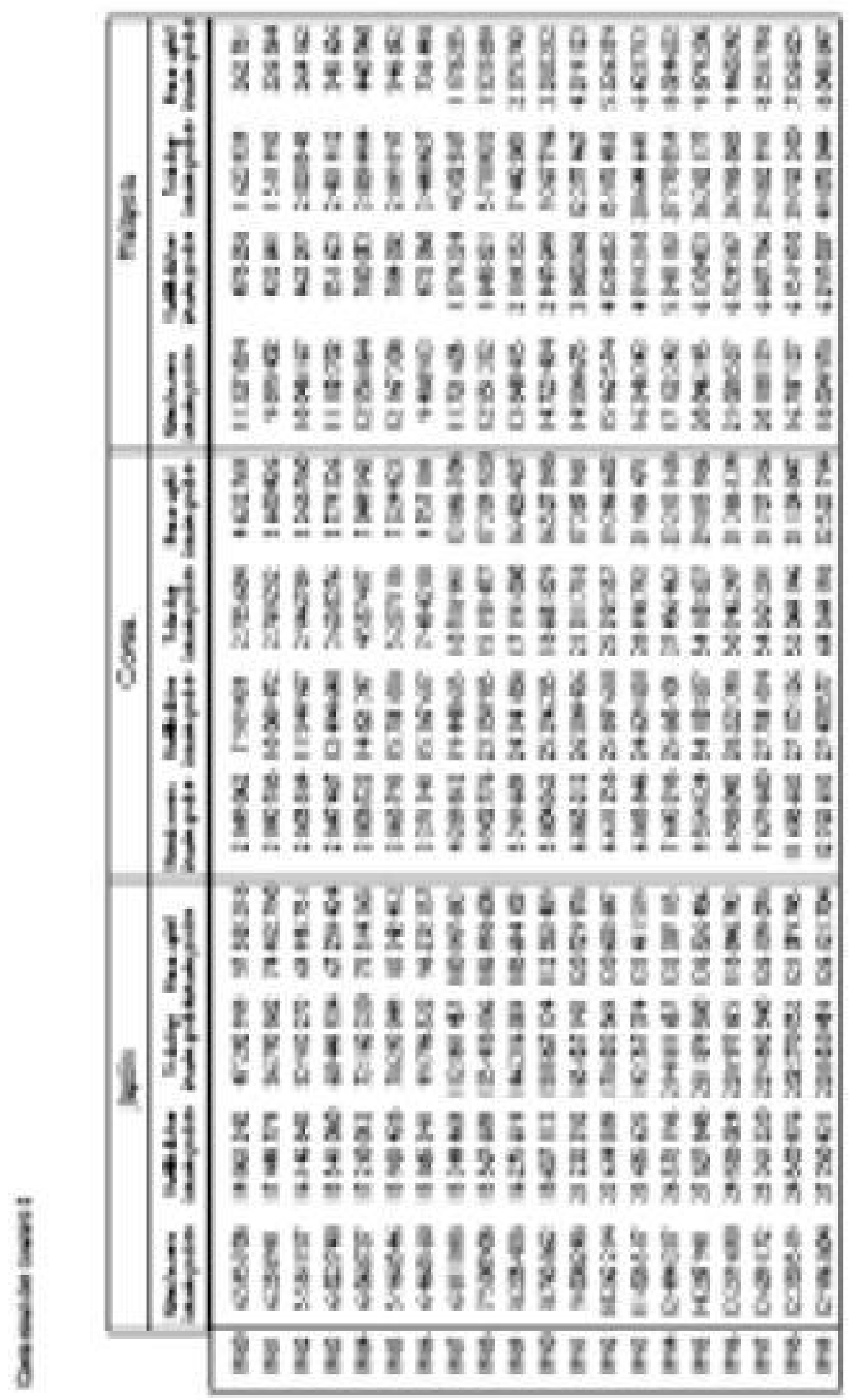




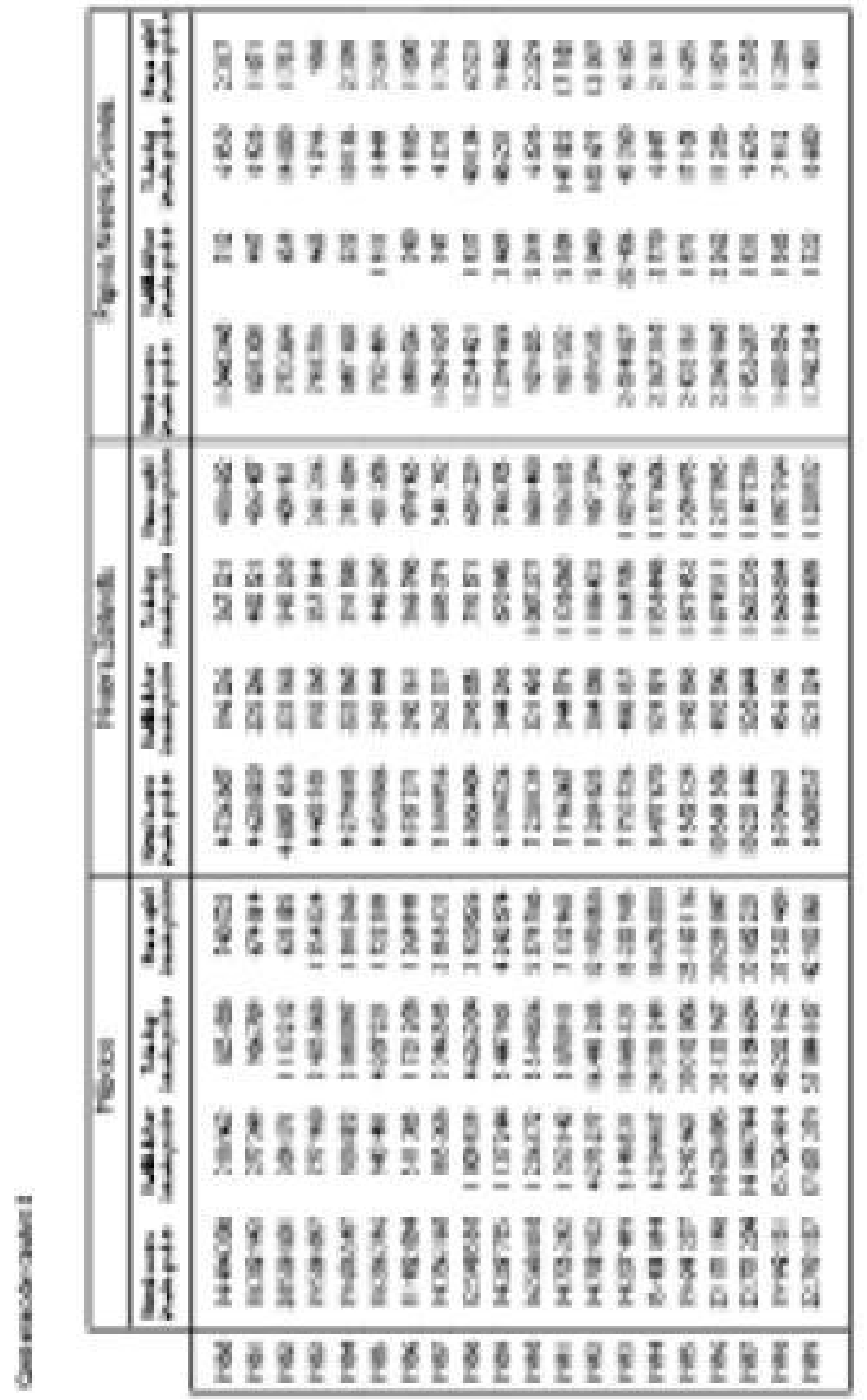




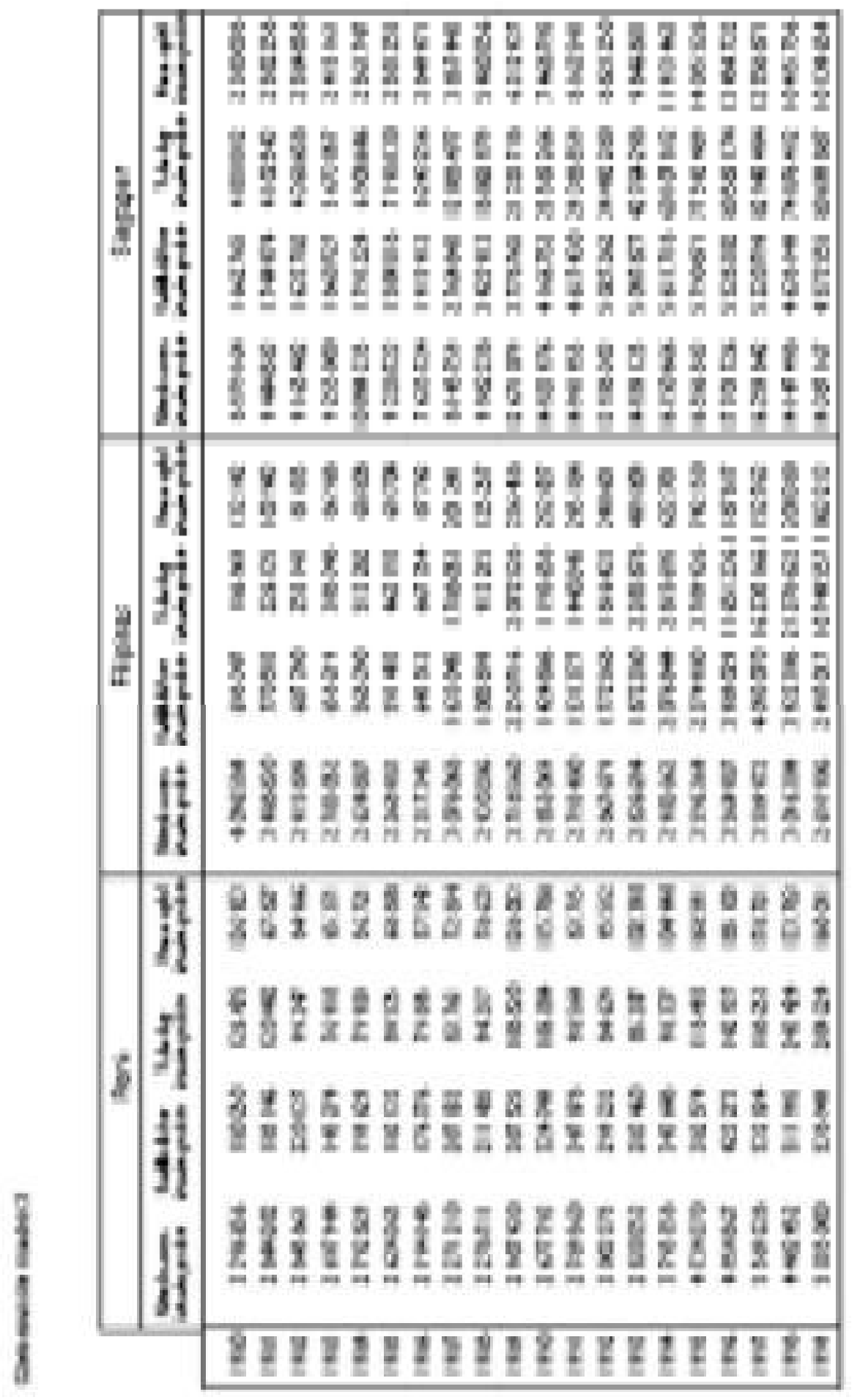




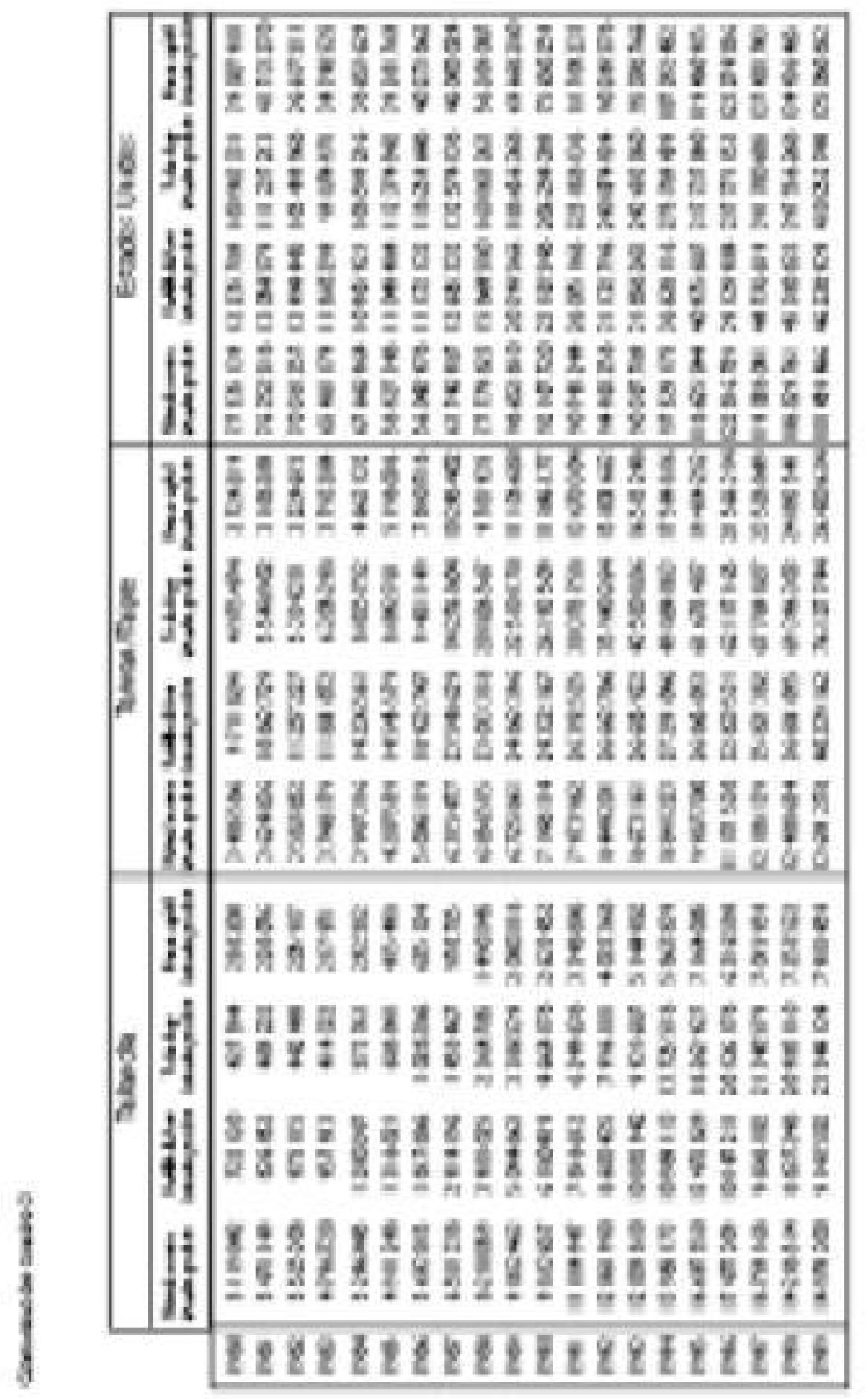




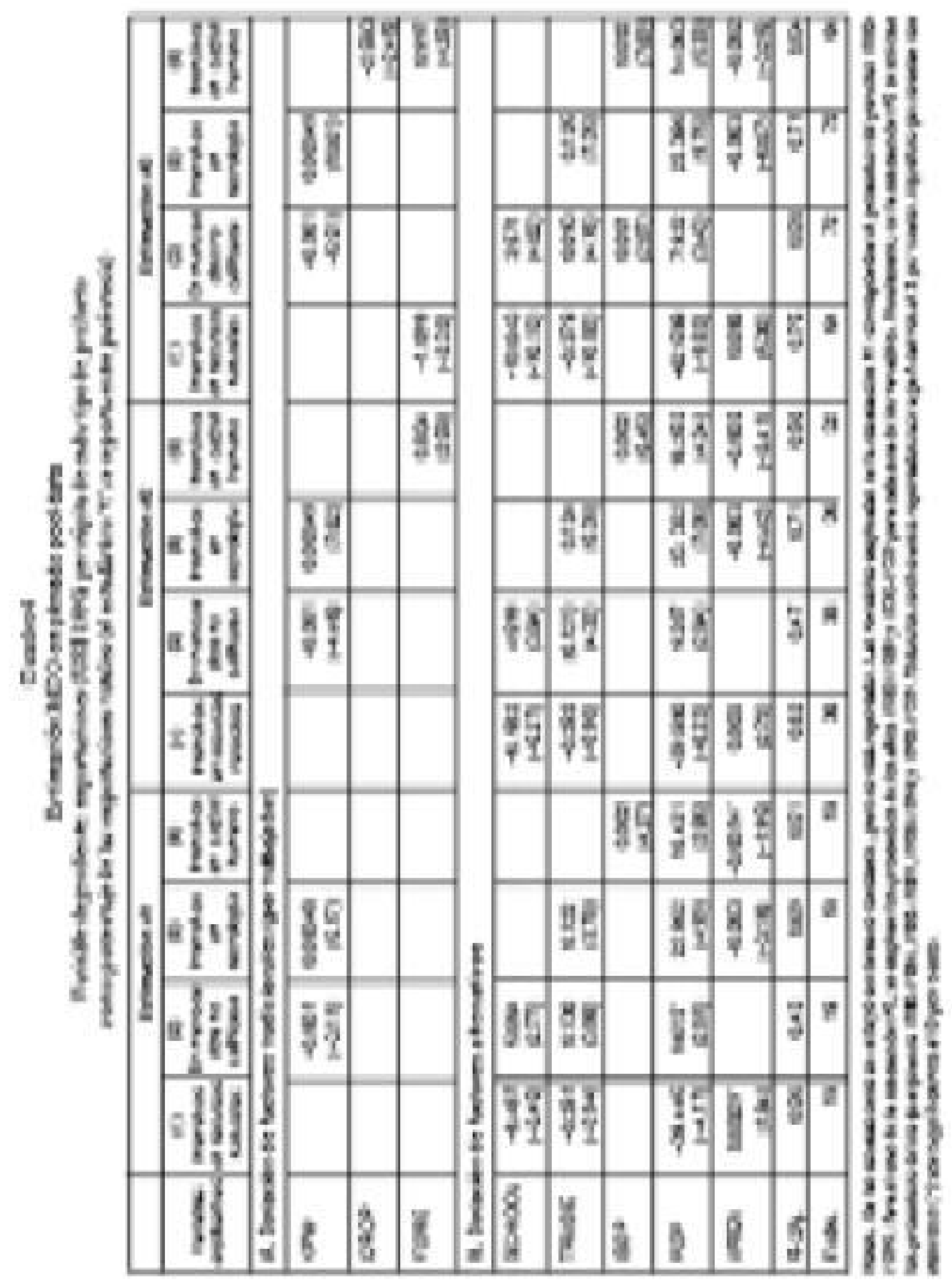

